\title{
Visual strength-grading and NDT of timber in traditional structures
}

Received (in revised form): 25th February, 2008

\section{Maurizio Piazza}

is Full Professor at the Department of Mechanical and Structural Engineering at the University of Trento and a member of a number of international and national technical committees. His research activity is mainly devoted to the themes of steel, composite steel-concrete, timber-concrete and timber structures. As regards the latter theme and in particular the existing timber structures, the research areas deal with traditional connections, mechanical characterisation, static and seismic behaviour, rehabilitation procedures as well as fire resistance.

\section{Mariapaola Riggio}

is an architect and has a PhD in Structural Engineering. She is a member of the RILEM technical committee AST for the 'In-situ assessment of structural timber'. She has carried out research activities in fields typical of structural rehabilitation, initially at the University of Calabria (UNICAL) and currently at the University of Trento. Her research and professional interests are mainly focused on the appraisal and restoration of existing structures.

Correspondence: Maurizio Piazza, Department of Mechanical and Structural Engineering (DIMS), Trento University, Via Mesiano 77 , | 38050 Trento, Italy; Tel: + 390461 882535; Fax: + 390461 882599; E-mail: maurizio.piazza@ing.unitn.it

\begin{abstract}
In order to assess the safety of old timber structures and eventually to select appropriate strengthening strategies, the evaluation of mechanical properties of the material is of key importance. Visual strength-grading coupled with the use of nondestructive in situ testing allows these properties to be determined. Nowadays, the definition of both nondestructive testing (NDT) procedures and criteria for the results interpretation are almost exclusively in charge of the producer. In Italy, effort has been made to develop codes for grading timber on-site, and also by means of NDT. The aim of this paper is to highlight the difficulties and shortcomings that still occur in the assessment of traditional timber members following the criteria established by the legislation in force in Italy. The presented results can be helpful for the building surveyor who is in charge of the inspection of existing timber structures. Indeed, the paper gives some indications on the effectiveness of the grading criteria applied on historical timbers, as well as on the level of accuracy of some nondestructive methods.
\end{abstract}

Journal of Building Appraisal (2008) 3, 267-296. doi:10.1057/jba.2008.4

\section{Keywords:}

timber, visual grading, on-site grading, traditional structures, NDT

\section{INTRODUCTION}

In order to assess the safety of old timber structures, evaluation of the actual mechanical properties of the material represents a first step towards diagnosis, structural analysis and the definition of possible strengthening strategies. The mechanical characterisation of timber elements on-site, especially of those that serve as load-bearing structures in buildings of cultural interest, requires the avoidance, or at least the limitation, of damage to the structure and the single elements. In this case two alternative and complementary approaches are visual strength-grading and the nondestructive measurement of properties. Both approaches, however, always include some uncertainty because of factors dependent 
on the peculiarity of the material as well as on measurement error and correlation inaccuracy. As regards the former aspect, structural timber can be characterised as a highly anisotropic and inhomogeneous material. Anisotropy implies that wood is an oriented material whose strength and stiffness in the growth direction of the tree stem (along the fibres) are much higher than in the transverse plane. Heterogeneities occur at different levels of organisation of the material, from the microscopic to the structural scale. At the macroscopic level, mechanical properties are affected by defects such as knots, reaction wood, checks and shakes.

Visual strength-grading criteria take into account these macroscopic characteristics, together with clear wood properties and building defects, in order to assign lumber members to an established strength class. Originally, grading rules were conceived to sort lumber within the sawmill production rather than to evaluate timber in existing structures. Efforts have been made in some nations to develop codes for grading timber on-site, ${ }^{1}$ but they still prove to be inadequate to satisfactorily meet the full range of cases actually occurring.

The aim of this paper is to highlight the difficulties and shortcomings that still occur in the assessment of traditional timber members following the criteria established by the legislation in force in Italy, where a large amount of resources are devoted to the repair and rehabilitation of existing structures (Piazza and Del Senno, 2001; Macchioni and Piazza, 2006).

The presented results can be helpful for the building surveyor who is inspecting existing timber structures for the purpose of their conservation. Indeed, the paper gives some indication on the effectiveness of the grading criteria applied on historical timbers as well as on the level of accuracy of some nondestructive methods.

For this purpose a wide experimental campaign on disassembled old roof beams has been undertaken at the DIMS (Department of Mechanical and Structural Engineering) laboratory of the University of Trento (Italy).

The two main grade-determining properties that have been measured are bending strength and stiffness. Indeed, bending is the most common loading mode in the structural use of sawn timber and consequently bending strength usually is the critical strength property. On the other hand, bending properties are straightforward to measure by means of direct methods (loading tests).

To visually grade timber, strength-grading criteria established by the Italian standards (UNI 11035:2003, UNI 11119:2004) were adopted.

Two nondestructive methods, the hardness test, as adapted by Piazza and Turrini (1983) for on-site tests, and ultrasound testing, have been used to indirectly measure the stiffness of timber. The results of both measurements as well as of visual grading have been compared to the stiffness as directly measured through bending tests. Finally, test material was loaded to failure, in accordance with the European Standard EN 408 (CEN, 2003c), to obtain its strength. The obtained results have been compared with the strength characteristic values of the graded timber.

Results of the visual strength-grading have been compared to the destructive data in order to evaluate the reliability of the two standards in force in Italy in predicting bending strength. Density has also been treated as a grade-determining property and values obtained by direct weighting have been compared with nondestructive measurements and mean values of the strength classes.

In addition to the experiments performed on full-size elements, tests on portions of old beams at both equilibrium moisture content (EMC) and fibre saturation point (FSP) were carried out in order to evaluate the influence of the moisture content (MC) on the results 
of the on-site grading. Indeed, the influence of such important environmental factors on the mechanical behaviour of the material must be taken into account by the grader.

\section{VISUAL STRENGTH-GRADING AND NONDESTRUCTIVE TESTING: THE TWO APPROACHES}

Traditionally, the surveying of timber structures is based on visual inspection, which consists of examination and recording of wood features, defects, signs of damage or deterioration, sometimes with the help of simple instruments (hammer, screwdriver, chisel, etc).

Visual inspection is also the basis of any form of strength grading on-site. Moreover, the complementary use of testing tools during the inspection is a precursor to any nondestructive testing (NDT) method used on-site. Indeed, stress waves methods can be considered a descendant of the old practice of knocking on a wood member with a hammer in order to evaluate the 'impact sound' and, from here, the 'soundness' of the material. Similarly, the use of a knife or spike to test the substance of the wood and eventually assess the extent of decay is a forerunner of the sclerometric and microdrilling tests.

Today, design standards require quantitative and not merely qualitative parameters to be used in the computations. Therefore, scientifically founded and partially standardised methods have been developed to evaluate the wood material to infer the engineering design properties.

Among the mechanical properties, bending stiffness and strength must be determined in order to assess the serviceability and the safety of timber elements such as simple supported timber beams used in floors and roofs.

Although other properties can be measured nondestructively, true strength can only be determined in a destructive test. Clearly, such an approach is rarely acceptable in historic buildings, owing to the permanent loss of the pieces tested. Therefore, practically all strength grading is based on indirect methods where measurements or observations of other properties of timber pieces are used to predict the strength. The strength of timber can be predicted by the measurement or quantification of characteristics that have a clear effect on it or on those measurable properties that do not directly affect strength but are good indicators of it.

Macroscopic strength-affecting characteristics, such as knots, are measured through visual strength-grading. On the other hand, NDT methods assess strength by measuring one or more predictor parameters that can be correlated with it. Stiffness, for instance, as well as energy storage and dissipation properties of wood (Jayne, 1959) are not direct factors to define strength, but, because they are dependent on the same factors that define strength, are good indicators of it.

The ability of a grading system to estimate strength (and other grade-determining properties) depends upon how reliably the measured characteristic(s) can predict the true strength of the timber, and how accurately the characteristics can be measured.

The uncertainty of predictions of strength has been dealt with in the strength-grading system by setting requirements to the statistical distribution of the grade-determining properties of timber pieces that fall into a certain strength class (EN 14081, CEN, 2000). The whole development of strength-grading criteria implies the demonstration that the required statistical properties can be met with a sufficient confidence level.

The European standard EN 338 (CEN, 2003b) defines 12 strength classes of sawn softwood timber, C14, C16, C18, C20, C22, C24, C27, C30, C35, C40, C45 and C50, and six classes of hardwood timbers, D30, D35, D40, D50, D60 and D70, where the number 
after ' $C$ ' and 'D' refers to the characteristic value of bending strength (in MPa) of timber pieces graded to that particular class. The characteristic value (denoted with subscript $k$ ) is defined as the fifth percentile value, which means that 5 per cent of the pieces graded in the class may have a lower strength value than indicated by the strength class characteristic value and at least 95 per cent exceed it. To ensure that even the few pieces with strength below the characteristic value will not fail during service, safety factors that account for the material and loads uncertainty are introduced into the codes.

In addition to the requirement for bending strength, the European standard sets requirements for two other properties: density (mean and characteristic value) and bending stiffness (mean value of modulus of elasticity $(\mathrm{MoE})$ ). These three properties of timber can be named as the grade-determining properties. All other strength properties and elastic moduli are assumed to follow, if the three grade-determining properties are shown to be satisfied by the graded timber.

Historically, both visual strength-grading and NDT techniques have been developed and used almost exclusively for sorting or grading new timber in the sawmill. Both approaches, however, can be adopted to provide information pertaining to the loadbearing capability of timber in place in a structure. The main difficulty of the surveyor is the lack of standardised references to many NDT techniques that are on the market.

If the definition of NDT procedures and results reading criteria are almost exclusively in charge of the producer, formal rules for visually grading new timber were established already at the beginning of the 20th century. In 1927, the USA ASTM Standard D245 defined the guidelines for developing strength-grading rules based on visual sorting criteria (Madsen, 1992).

From the 1930s onwards, grading rules were introduced in various European countries. National codes developed over the last 70 years differ widely with respect to grading criteria, number of grades and grade limits. These have come into existence to allow for different species or groups of species, geographic origin, different dimensional requirements, quality of material available as well as historic influences or traditions.

In order to unify visual grading criteria in Europe, general guidelines were issued by the EN 518 in 1997. Thereafter national standards were developed on the basis of the European code in order to establish strength classes for local timbers.

\section{VISUAL GRADING CRITERIA}

The strength and stiffness properties of timber depend on the clear wood properties as well as on the presence and type of defects. In particular, clear wood has a stronger effect on stiffness because stiffness is to a greater degree determined by average properties than by local weak spots. Failure path and strength in structural timber, instead, depend especially on variation in material properties and local defects, which are caused by various growth characteristics but also by timber handling and manufacturing.

Since wood is a porous material, variations in the size of the cell cavities and the thickness of the cell walls cause variations in its specific gravity. Thus, specific gravity is an excellent index of the amount of wood substance contained in a wood sample, and, consequently, it is a good index of mechanical properties as long as the wood is clear.

For many softwoods, such as spruce, density is inversely related to ring width, as growth rate affects the width of the earlywood, whereas the amount of the denser latewood remains more or less constant. Therefore, ring width is included in the timber-grading criteria, and used as a rough estimate of density, and thus of stiffness and strength. 
Clear wood properties are also influenced by the orientation of the 'strengthening structures' of the material at various scales: the microfibril in the cell wall and, at a lower level of magnification, the wood fibres.

The deviation of fibre can be macroscopically determined by measuring the orientation of its projection on the element faces: the grain.

Because truly straight-grained timber is the exception, the extent and degree of grain deviations is an important consideration when using wood for structural purposes.

The 'slope' of grain (SoG) is the deviation of the grain from the edge of the piece or from a line parallel to its principal geometrical axis. The main causes of grain deviations are diagonal grain and spiral grain. The latter is a growth characteristic, whereas the former is either due to the taper of the stem or caused during sawing.

Several studies have been carried out over the last century in an attempt to quantify the effect of global SoG on both bending strength (expressed as a modulus of rupture (MoR)) and stiffness (expressed as MoE) (ie Luxford, 1918; Wilson, 1921; Brazier, 1954; Pope et al., 2005). Zhou and Smith (1991) investigated the various factors that influence bending properties and found that the effect of SoG was of much less significance than the presence of knots and relative density. It was noted though (Sunley, 1968) that SoG effects were at least twice as great for structural sizes than for small clear test specimens.

Both natural defects and deterioration of wood have a detrimental effect on the mechanical properties of the material. Deterioration caused by biotic attack causes a decrement of the original 'quality' of wood, not only because of the general decrease of density but also because of the chemical alteration of the wood substance, as in the case of decay caused by rot.

Among the natural defects of timber, knots are considered the most severe. Their strength-reducing effect is most likely caused by a combination of local grain deviation and reduction of the clear wood area in the cross-section, even if the former factor is the most significant (Kollmann and Côté, 1984). Most of the visual strength-grading systems are based mainly on the size of knots and their location. Knots alone are, however, poor strength predictors. The correlation between knot size and strength varies with species and depends on the way in which their effect on strength is evaluated.

Different visual grading criteria have been developed and adopted by various national standards to measure knots. The KAR (knot area ratio) criterion takes into account the incidence of knots within the cross-sectional area. Marginal KAR and total KAR criteria permit evaluation of the incidence of knots on the basis of their position in sawn timber. In fact, the former considers, as reference area, just the edge of the element (generally $1 / 4$ of the cross-section total height).

The knots' geometry is approximately a cone radiating from the pith. Consequently, the KAR can be computed considering the projection of the cone on the correspondent crosssection. This is generally possible in relatively thin boards, in the case the knot is visible on two faces of the element, or conversely in un-sawn timbers or large scantlings including the pith.

A simplified criterion considers just the superficial incidence of knots. In this case, maximum dimensions of knots are specified, on the basis of linear values, as the ratio of the sum of the knots' diameters to the edge of the face where knots appear. For certain species and sizes, the presence of knot clusters is also taken into account.

In the Italian standard UNI 11035:2003, single knots are measured considering the ratio of the minimal diameter to the width of the element face, whereas knot clusters are evaluated through the ratio of the sum of the minimal diameters of all the knots located within $150 \mathrm{~mm}$ of the timber length to the width of the element face. In case of old timber, 
if the area where knots occur is decayed or damaged, the width of the residual crosssection must be considered, according to UNI 11119:2004 § 7.5.1.3.

In the British codes, the KAR method is adopted by the BS 4978:1996 (for softwoods) whereas the BS 5756:1997 (for hardwoods) considers just the knots' diameters on the correspondent faces. The latter method is also adopted by the French AFNOR B52-001-04:1991.

In the German DIN 4074: 2003, knots' diameters, or 'equivalent diameters' in the case of spike knots, are referenced to the edge of the face where they are measured.

The Swiss SIA 265/1:2003 considers the incidence of knots taking into account the size and shape (sawn or round timber) of the element as well as the orientation of the annual rings (tangential or radial boards). In particular, the KAR criterion can be used in the case of round timber, the sum of diameters of the knots appearing on all the faces is considered in the case of boards, and in thicker elements the incidence on the single face is taken into account.

In the prEN 14081-1:2000 the criterion based on diameter values and the one based on KAR values are both permitted; moreover, knots can be measured 'in relation to absolute values for a given range of timber sizes'. The standard also states that 'different limitations on knot sizes can be specified for different portions of the piece, e.g. a margin area with different knot limitations from the rest of the piece may be included'.

The prEN 14081-1 establishes criteria for the strength grading of structural timber with rectangular cross-sections and deviating from the target sizes corresponding to EN 336. The draft standard is a first attempt to fill a gap of today's European standards, which neglect size effect on grading criteria. Indeed, the European standards in force give just the minimal dimensional limits of the graded timber (ie BS 5756: minimum thickness $=20 \mathrm{~mm}$ ). In the American codes, the effect of size on strength is taken into account by specifying two procedures for calculating size-adjustment factors: 'small clear' (ASTM D245) and 'in-grade' (ASTM D1990).

It is well known that the strength of timber decreases with size, because the larger the stressed volume, the higher the probability that a weak link occurs in the volume (Weibull, 1939). This means that, in general, size effect causes small members to have greater unit strength than large members.

Moreover, size effect makes strength grading more complex, because the influence of different parameters depends on the cross-section size. Indeed, it has been found that the influence of density and stiffness on determining strength decreases, and the effect of knots increases for small scantlings (Adelhøj et al., 1984, Foslie and Moen, 1972, from Hanhijärvi et al., 2005). This seems natural because in small cross-sections knots constitute a larger portion of the total area (Barrett and Fewell, 1990).

Furthermore, in large scantlings, variability of the properties is greater across timber thickness when compared with the variability along the timber (Kasal and Anthony, 2004).

In current legislation, grades are referred to specific commercial timber sizes, which differ from the typical traditional scantlings; consequently, the criteria used for new timber elements are not able to properly take into account size effect in old timber.

As regards the shape of the element, visual strength-grading criteria also establish limitations for geometrical characteristics, such as wane and distortions, because they are accounted for building defects. In particular, the presence of wane can be a defect in case of ample bearing or nailing surfaces. Geometrical limitations, however, penalise traditional timber members. Indeed, waney-edged and tapered elements, obtained by roughly cutting the logs, are typical of massive large scantlings, as in most traditional roofs, slabs and load-bearing elements in the Mediterranean area. 
The probability of failure is influenced not only by geometry and size of the element but also by load conditions and load configuration, which are unpredictable while grading new products, but are known for timber on-site. Therefore, in the case of on-site timber members, the position of defects along and across the element should be considered with reference to the acting stresses. Knots, for instance, reduce the MoR of wood considerably if they are located in the tension zone near the critical cross-section; conversely, transverse compression strength, hardness and shear strength increase with the presence of sound, tight knots, which behave as pegs.

Currently, the need to relate the occurrence of defects to the stress distribution in a member, in deriving grading rules for timber on-site, has been pointed solely by the Italian standard UNI 11119:2004.

Nevertheless, there is, at the international level, the need to define a standard methodology for the acquaintance of cultural heritage, as is demonstrated by the work of technical committees such as the RILEM (International Union of Laboratories and Experts in Construction Materials, Systems and Structures) Technical Committee AST for the 'In-situ assessment of structural timber' (www.rilem.net).

\section{STRENGTH GRADING OF TRADITIONAL TIMBER: THE METHOD}

\section{The test material}

A thorough investigation on beams of disassembled old roofs has been carried out at the DIMS laboratory of the University of Trento in order to compare results of visual grading with the data gathered from NDT as well as destructive tests.

Both visual grading and NDT require some preliminary investigations, namely species identification and MC measurement. The wood species of the test materials were spruce (Picea abies Krast.) and larch (Larix decidua Mill.) from north Italy, and chestnut (Castanea sativa).

Full-size elements were graded at their EMC. Elements at a smaller scale, obtained from portions of old beams, were tested at both EMC and FSP in order to evaluate the influence of $\mathrm{MC}$ on the grading methods. To determine properties of saturated wood, specimens were soaked in clean water up to the moment of testing, in order to maintain MC at the FSP.

Most of the material was from the old timber roof of 'Ai Caduti dell'Adamello' refuge, on the Adamello glacier in Lobbia Alta (Italy). In order to properly simulate the on-site grading, the original static scheme of the beams was recorded before dismantling the roof: span and orientation of the cross-section were marked on each element, whose position was sketched on a map.

Elements were measured at every $100 \mathrm{~cm}$ and each cross-section was represented with its actual shape and dimension, as well as its spatial position along the axis, to take into account any contingent distortions. Most of the elements were characterised by the presence of geometrical irregularities, notches and wanes. The presence of notches, in apparently incongruous positions, was because most of the beams of the refuge's roof are second- and even third-hand timbers, as proved by dendrochronological analysis (Pezzo and Zamatteo, 2006) (Table 1). Indeed, the refuge was built in 1929 using the dismantled timber of a camp built during the First World War, and the camp itself was made by recycling timbers of the barracks at a lower pass on the Adamello glacier.

\section{MC measurement}

Timber in place is often characterised by a nonuniform MC along and within the element. In particular, in beam ends buried into masonry, an inverse moisture gradient, increasing 
Table I: Species identification and dating of the timber elements (Pezzo and Zamatteo, 2006)

\begin{tabular}{llll}
\hline Beam & Timber dating (dendrochronology) & Building chronology (recycled elements) & Species \\
\hline I-A & 1888 & 1929 & Picea abies Karst. \\
2-A & 1916 & 1929 & Larix decidua Mill. \\
3-A & 1879 & 1929 & Picea abies Karst. \\
4-A & 1917 & 1929 & Picea abies Karst. \\
5-A & 1892 & 1929 & Picea abies Karst. \\
6-A & 1907 & 1929 & Picea abies Karst. \\
7-A & 1916 & 1945 & Larix decidua Mill. \\
8-A & 1901 & 1945 & Picea abies Karst. \\
9-A & 1910 & 1945 & Picea abies Karst. \\
I0-A & 1942 & 1945 & Picea abies Karst. \\
II-A & 1941 & 1945 & Larix decidua Mill. \\
\hline
\end{tabular}

from the core of the beam outward, often occurs. MC measurement is important for correct grading, because of the influence of MC on many properties of wood such as weight, shrinkage and strength; moreover, the presence of dampness is associated with the risk of rot in timber, and therefore of decayed material.

$\mathrm{MC}$ in wood represents the proportion of water compared with the proportion of anhydric material. It is defined as the weight of water in wood expressed as a percentage of the weight of oven-dried material:

$$
M C_{\%}=\frac{\text { Weight }_{\text {test }}-\text { Weight }_{\text {ovendry }}}{\text { Weight }_{\text {ovendry }}} \times 100
$$

From 0 per cent to $25-30$ per cent water is held chemically (bound water) within cell walls. When all the wood hydroxyl sites are saturated, MC has reached the FSP. At and beyond the FSP, water is free in the wood cells, and its influence on the wood properties is much less important.

Wood absorbs moisture from humid air and desorbs it to dry air, or precisely speaking, it tends to EMC with the surrounding environment.

When arranging strength tests according to the standardised methods (EN 384, CEN, 2004b; EN 408, CEN, 2003c), test pieces are first allowed to attain the EMC in the standard conditions - temperature $T=20^{\circ} \mathrm{C}$ and relative humidity $\mathrm{RH}=65$ per cent - and then tested. At these conditions the EMC for most softwoods is about 12 per cent. Visual strength-grading criteria also establish a reference MC that, in the Italian standard UNI 11035 , is equal to 20 per cent.

The oven-drying, distillation and electrical methods for determining $\mathrm{MC}$ are covered in ASTM D4442; the oven-drying and electrical methods are also described in EN 13183, parts 1 and 2, respectively (CEN, 2002a, b). The latter is the principal method used for wood in place in a structure. It was developed during the 1940s (Dunlap and Bell, 1951) and uses the relationships between MC and measurable electrical properties of wood, such as conductivity (or its inverse, resistivity), dielectric constant or power-loss factor.

Both capacitance and power-loss type instruments work over the full range of MC and are, for practical purposes, independent of ambient temperature. They are applied to the surface, with no penetration, so they can be considered totally nondestructive. The readings will, however, only give a value of $\mathrm{MC}$ if the density of the wood is known.

The resistance moisture meter is based upon the measurement of electrical resistance between two probes put into contact with the timber. The correlation between resistance and MC varies slightly between species, but the meter has differently calibrated scales, from which the MC can be read directly. Although some meters have scales that go up to 


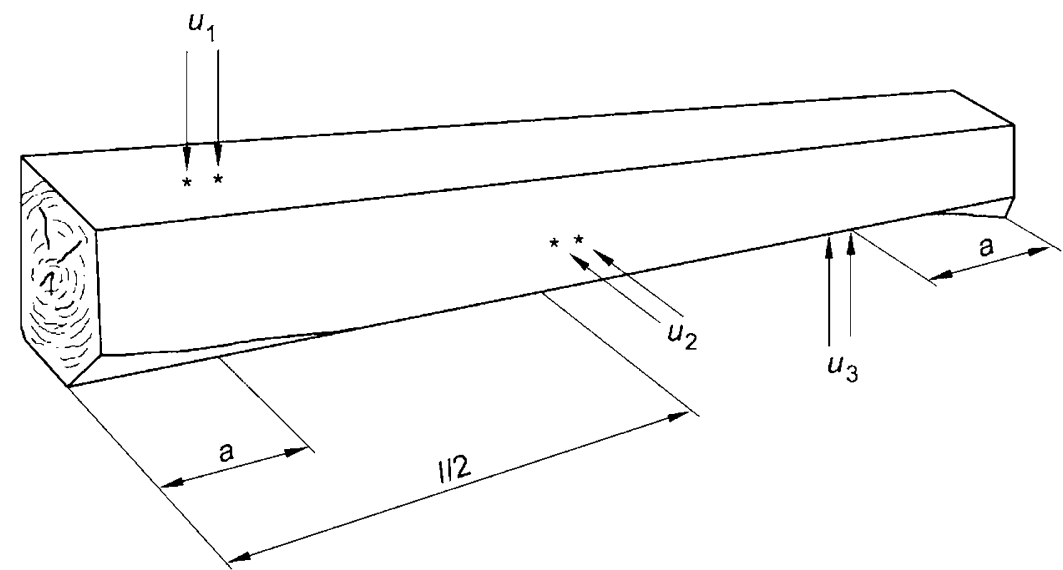

Figure I: Average MC measurement (UNI I I035)

120 per cent, the range of MC that can be measured reliably is about 6-30 per cent for commercial resistance meters.

A resistance moisture meter was used, before grading the test material in order to indirectly measure the average MC. Insulated needle electrodes were driven into about one-third the thickness of the wood to determine the average MC of the entire piece.

According to UNI 11035 the measures on three faces of each element were averaged (Figure 1):

$$
U_{\text {average }}=\left(u_{1}+u_{2}+u_{3}\right) / 3
$$

\section{Density determination}

Density can be considered as a grade-determining property in case its value, directly or indirectly measured, is used to derive other correlated mechanical parameters. On the other hand, characteristic and mean density values can be assumed for visually graded timber according to the strength class assigned to the element.

Correlations between mechanical properties and density were reported by several authors (Kollmann and Côté, 1984; Bodig and Jayne, 1982; Giordano, 1999; FPL, 1999) for different species. In general, density is a good predictor for the strength of clear, defect-free wood. In investigations on structural timber (Zhou and Smith, 1991), density was found to better correlate with load-carrying capacities if determined near the area of rupture.

Density is defined as the mass of unit volume. For practical computations the mass is determined by dividing the weight by the volume. Because MC affects both volume and weight of a wood sample, it is necessary to specify the MC at which specific gravity is measured.

The reference $\mathrm{MC}$ for visual strength-grading is 20 per cent. Where the density is given at an MC other than 20 per cent, correction factors shall be available for correction to 20 per cent. The EN 384 (CEN, 2004b) gives 0.5 per cent of increment or decrement as correction factor for each percentage point of MC less or more than 12 per cent, respectively. According to the EN 408 standard (CEN, 2003c), given the conditioning of the specimens, the average density is determined, for an $\mathrm{MC}$ of 12 per cent, by

$$
\rho_{12 \%}=\frac{m_{12 \%}}{V_{12 \%}}
$$


Here, $m$ indicates the mass and $V$ indicates the volume of the whole element.

In the case of timber on place, because of the impossibility of weighing the whole element, direct density measurement can be carried out on samples. The effectiveness of this method depends, of course, on the number, type and position of samples, whereas its feasibility is contingent on the principle of the minimal invasiveness of testing.

In the research reported in this paper, density was measured according to the EN 408 standard in order to gather the required input data for the NDT.

Direct determination of density of old timber elements in structural size can be tricky even in laboratory conditions. Indeed, even if the elements can be directly weighted, problems could still occur in volume determination, in the case of irregularly shaped elements (irregular and variable cross-sections, presence of splits and distortion).

Radiation densitometry, which measures the attenuation coefficient of X-rays or gamma rays, is an indirect technique for assessing the density characteristics of wood samples. The use of radiographic scanning system for in situ investigations of timber is, however, not widespread, because of both the scarcity of tailored portable equipment and the safety problems related to emitted radiation. Alternatively, local nondestructive test methods, such as the drill resistance measurement and the sclerometer test, can be adopted to measure the density of timber on-site.

The drill resistance measure by the Resistograph ${ }^{\circledR}$ device is based on the resistance offered by the material to the advance of a small-diameter drill bit. During the experimental campaign a total of 12 tests in three sections equally spaced along each element face were carried out. Rinn (1992) found that the mean resistance levels of the Resistographic profiles closely correlated with the gross density of dry wood from the $\mathrm{X}$-ray density profile. MC is inversely related to the drilling resistance.

Sclerometer testing, performed by means of the Pilodyn ${ }^{\circledR}$, measures the penetration of a steel pin driven into the wood with constant energy. Pilodyn measurements were taken on the test material, close to the ends and at the mid-span of each element. Görlacher (1987) found that the Pilodyn is able to predict mean outerwood density values with reasonable accuracy. The correlation between the depth of penetration and density also, however, depends on MC, number of measurements and species.

\section{Visual grading}

In the reported research work, grading criteria according to European (EN 518:1997) and Italian standards (UNI 11035-1-2:2003) have been applied. Moreover, the guidelines of the Italian UNI 11119:2004 concerning on-site inspections of timber members have been adopted in order to grade elements whose features did not meet the requirements of the categories used for new structural timber.

UNI 11035-1 defines the terminology and measurement of features for the visual strength-grading of Italian structural timbers. Hence, it defines reference MC; direct or indirect evaluation of the density, the latter performed by measuring the number of growth rings contained in a reference line; limits to defects reducing the strength (knots, SoG, checks, splits, shakes); and limits to geometrical features representing building defects (wane and distortion) and decay. The second part of the code (UNI 11035-2) contains visual strength-grading rules and characteristic values for Italian structural timber population. Grading rules are specified for different Italian timbers that are identified by coupling species and geographic origin. Timbers are assigned to strength classes by measuring the visual features specified in the first part of the code. Finally, strength values are referred to strength classes for each timber group. 
UNI 11035 is also valid for on-site grading; in this case, more criteria are established: (a) at least three longitudinal faces and one of the transversal faces of the element must be visible; (b) grading rules are applied to the residual resistant part of the element, deducted of the decayed parts. If the in situ element cannot be graded according to UNI 11035, its load-bearing capacity has to be otherwise estimated.

UNI 11119:2004 establishes criteria for the diagnosis of old timber members by means of on-site inspections and nondestructive techniques. Strength grading can be performed by coupling both visual criteria and NDT results. The former criteria can be applied just on the visible parts of the member. In case the accessibility and visibility of the wooden member's surface are limited and the visible faces are less than three, that circumstance has to be specified in the inspection report. The use of ND techniques is recommended where and when the presence of nonvisible alterations is suspected.

According to the UNI 11119 standard, timber in service can be 'piecewise' graded once the so-called critical areas are identified. The 'critical area' is defined as 'part of a wooden element with longitudinal axes no less than $150 \mathrm{~mm}$, which is considered to be relevant because of defects, position, state of conservation and also stress conditions which are determined by static analysis'.

While UNI 11035 establishes different grading criteria for different timber groups, in UNI 11119 the same grading criteria are applied to all species.

Another important difference between UNI 11035 and UNI 11119 is that the former provides characteristic strength, stiffness and density values, which are fifth percentile values, whereas the latter provides allowable stress values. The grades referring to the two codes can be compared; deriving the characteristic values by the allowable ones by means of Equation (4) (Piazza et al., 2005):

$$
\sigma_{A}=f_{k} \frac{k_{\text {mod }}}{1.5 \gamma_{\mathrm{M}}}
$$

with $k_{\text {mod }}$ being the modification factor used in Eurocode 5 (EN 1995-1-1:2004) for taking into account the effect of the duration of load and MC (the value that can be used for comparison is 0,8$)$ and $\gamma_{M}$ is the partial factor for the material property $(1,3$ as proposed in Eurocode 5).

Grading criteria referred to the group 'softwood 1' in UNI 11035-2 $\S 5.3$ have been adopted for both larch and spruce timber, while criteria of the group 'hardwood' were applied for grading chestnut elements. The standard provides three grades for softwoods (S1 for the less defective elements), whereas hardwoods can be considered either admissible for structural uses (grade S) or not (NC). Three grades for timber in service are also provided by UNI 11119 for both softwoods and hardwoods.

Differently from on-site, in the lab the elements were completely visible and defects could be better examined because of proper lightning and treatment of the surfaces. Hence, all the defects, present on each face, were localised, measured and mapped.

In order to better examine the entity of knots, the surrounding areas have been polished.

The extent to which knots affect the strength of a timber element depends upon their position, size, number, direction of fibre and condition.

Knots were measured according to UNI 11035, on the basis of linear values, as the ratio of the diameters to the width of the element face. For decayed elements, the width of the residual cross-section was considered, according to UNI 11119 § 7.5.1.3.

The 'slope' of grain is usually designed by the ratio of a unitary deviation of the grain from the edge to the distance along the edge over which the deviation occurs. 
The grain is the projection of the wood fibres onto the measurement surface. Grain on LR (longitudinal-radial) faces describes stem tapering, and in the absence of spiral grain, it also corresponds to fibres' direction, whereas on pure LT (longitudinal-tangential) faces the slope due to spiral growth can be measured.

Normally, strength grading based on visual methods is limited to consideration of surface grain angles in the wide-face plane of boards. In traditional timber structures, whose elements are mainly beams instead of boards, all four longitudinal faces of the elements have to be considered. In UNI 11119:2004, different limits to SoG are set for LR and LT faces, in particular stricter limits are set for LR slopes.

In general, the overall SoG can be considered as the result of both cross grain and spiral grain; the former is expressed by the ratio $B C_{r} / A C_{r}$ determined on the radial face, whereas spiral grain can be measured on the tangential face by means of the ratio $B C_{r} / A C_{t}$ (Figure 2). Consequently, the global SoG is given by

$$
S o G=\sqrt{\left(B C_{r} / A C r^{2}+B C_{r} / A C_{t}^{2}\right)}
$$

In the analysed timber, the approximate SoG was often not evident from visual inspection, except for the few portions of prepared or planed timber. Therefore, general SoG on rough sawn timber was detected by measuring the inclination of contingent shrinkage splits on the longitudinal faces or, alternatively, the inclination of the grooves drawn by means of a scribe (Figure 2). The scribe test has also been used to indicate grain angle of roundwood, once the axis of the log was found. For this purpose, devices can be used, such as the one described by Wellner (1960), consisting of two sets of legs straddling the log, connected in length by a rod, whose direction can be adjusted according to the direction of pointers bisecting the angle between each set of legs.

All the defects, causing discontinuities in the tissues, such as checks, splits and shakes, can be considered equivalent to cracks. Checks are ruptures in wood along the grain, which, with the exception of heart checks, develop during seasoning. Unlike checks, splits are separations that extend through the timber from one face to another. Different kinds of shakes can occur: ring shakes are separation along the growth ring while heart shakes are ruptures radiating outward from the pith. Pitch defects are common in spruce and develop through an excessive accumulation of resin in localised regions. In particular, pitch pockets are plan-convex cavities between growth increments.

While shrinkage checks do not cause downgrading, if they are not developed into through splits, timber with shakes cannot be graded according to UNI 11035, except for internal shakes close to the pith. According to UNI 11119, timber with limited shakes can be assigned to the lowest strength class (III).
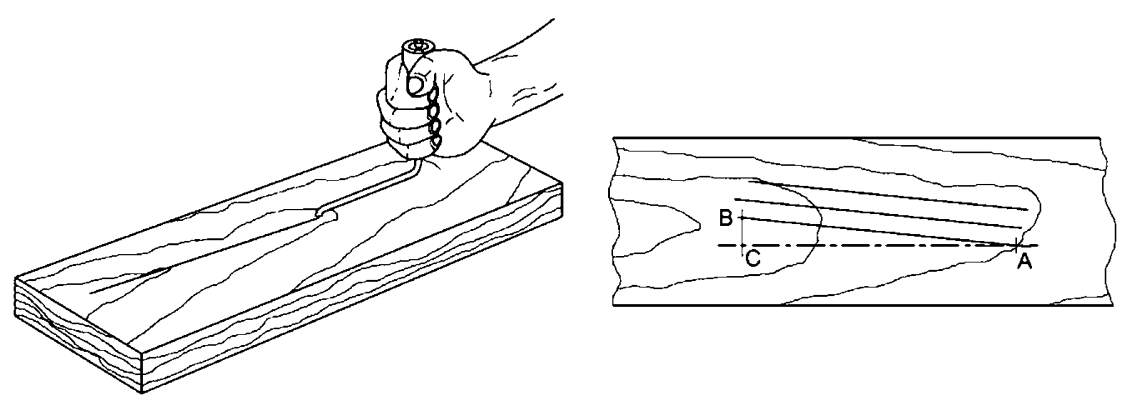

Figure 2: Scribe test (UNI I I035-I) 
The length of fissure and the amount of distortion are linked with MC; therefore, the limits given by the standard can only be applicable at the time of grading. For saturated wood $\left(u_{\text {mean }}>26\right.$ per cent), UNI 11035 contemplates the presence of 'prospective shakes' in the case of irregularly wide growth rings.

Biotic decay, such as rot or insect attacks, causes a reduction of the resistant cross-section. Decayed elements are rejected while grading new timbers, but in the case of old elements their presence is often unavoidable. Visual inspection enables the detection of external wood decay caused by rot, evidenced by the presence of fruiting bodies and mycelial fans, as well as that caused by insect activity, by the presence of insect bore-holes or, in case of recent attack, by the accumulation of sawdust. Internal decay is often masked by the lack of evidence on the exposed surface of the wood. Moreover, many hidden segments of timber in service, such as beam ends buried into masonry, are also the most vulnerable and exposed to decay. In this case, it is advisable to adopt local test methods in order to obtain information on the presence and extension of decay, and to determine the 'efficient section' defined as 'the cross-section of a wooden member (including defects) where the critical section is excluded from analysis and where actual wood degradation and/or damage are determined' (Figure 3).

In the reported research, sclerometer tests (Pilodyn) and measurements of the micro-drilling resistance (Resistograph) permitted one to analyse abnormal density variations, generally associated with mass loss, caused by biological degradation. In particular, Pilodyn was used to map surface decay, providing a rapid means of identifying areas that needed further investigation (Baldassino et al., 1996). The microdrilling resistance tests permitted one to assess the element residual section within each 'critical' area.

Frequently, decay is not extended to the whole element, but rather localised in critical points, such as those in contact with wall, where dampness stands. According to UNI 11119 , elements can also be partially graded with respect to each critical zone, thus permitting one to grade decayed or damaged timber.

In the case of fungal and insect attacks concentrated in a specific zone, a residual resistant cross-sectional area has to be considered. On the contrary, elements that are uniformly damaged by insects can be graded considering the whole element, not deducted from the decayed parts. In this case, however, values of strength and stiffness must be reduced according to the severity of damage. The advisability and entity of this reduction are arbitrarily established by the grader.

As regards the geometrical features that are considered in the grading criteria, especially wane occurs in old massive beams. In fact in traditional buildings, large scantlings were often obtained by roughly cutting the logs in order to maximise the available material.

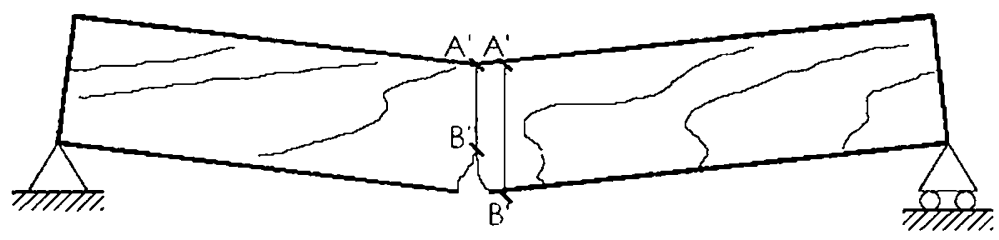

$\mathrm{A}^{\prime} \mathrm{B}^{\prime \prime}=$ critical section

$\mathrm{A}^{\prime} \mathrm{B}^{\prime \prime}=$ efficient section

Figure 3: Critical section and efficient section (UNI IIII9) 
The geometrical variability involves a considerable variation of the modulus of inertia along the element axis. This variation has to be taken into account in calculation, but cannot be considered as a strength-reducing characteristic.

\section{Hardness tests}

Hardness is generally defined as resistance to indentation. Actually, wood hardness involves compression strength, shear strength and fracture toughness.

Wood hardness is positively correlated to density and, as a consequence, to the material strength properties. Moreover, hardness is in inverse proportion to MC. For softwoods, hardness values of air-dried samples $(u \approx 12$ per cent) are $1.7-1.8$ higher than for green samples ( $u>35$ per cent).

Among the standard hardness tests, the modified Janka test, which measures the load required to embed an $11.28 \mathrm{~mm}$ ball to one-half of its diameter, is more similar to the method used in the reported research.

In the performed tests, hardness was estimated by measuring the load force $R$ required to embed a $10 \mathrm{~mm} \varphi$ steel hemispherical bit to $5 \mathrm{~mm}$ (Piazza and Turrini, 1983). The experimental test equipment is shown in Figure 4. The test area must be clear, that is, without visible defects. The value of $R$ was obtained by averaging the results of two tests for two opposite longitudinal faces, in particular at $1 / 3$ and $2 / 3$ of the span. Each test consisted of five measurements taken in each tested area. The result of each test was obtained by averaging the middle values among the five measurements. by

The correlation between $R$ and Young modulus in longitudinal tension $E_{0}$ is expressed

$$
E_{0}=\delta A R^{0.5}
$$

where $\delta$ indicates a reduction factor, $0.5 \leqslant \delta \leqslant 0.8$, that depends on the defectiveness of the element. $A$ is a coefficient that depends on the species of the tested sample, the value of the applied force and the MC.

The experimental force ranges from 700 to 3,000 N. For silver fir (Abies alba) and larch (Larix decidua) at an MC in the range of 12-14 per cent, the coefficient found by Piazza and Turrini is $A=350$. This value was used for both larch and spruce (Picea abies) elements. For chestnut (Castanea sativa), $A=263$ was proposed by Foresti (2006).

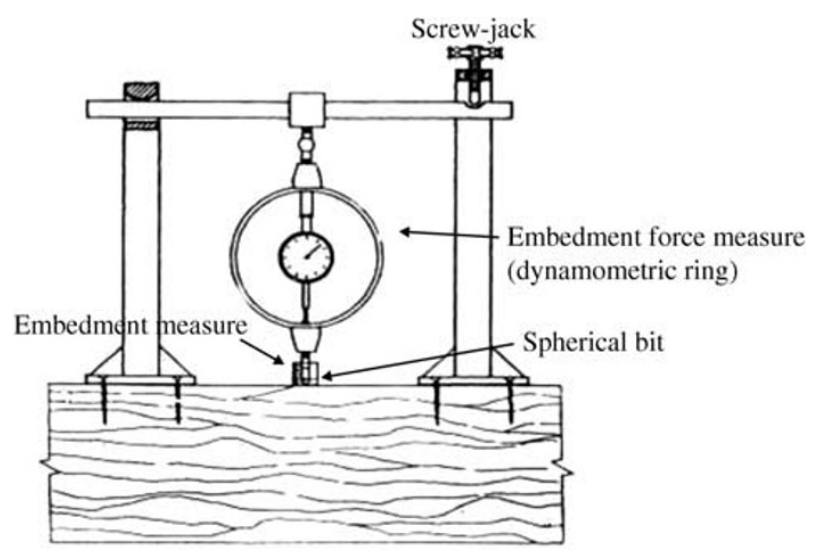

Figure 4: Hardness test device (Turrini and Piazza, 1983) 
In order to adjust the value of $E_{0}$ for different values of MC, the result of Equation (6) must be divided by a correction factor $C$ (Foresti, 2006)

$$
C=\left(1-0.0079 \Delta_{U 15-u[\%]}\right)
$$

where $\Delta_{U 15-u[\%]}$ is the difference, in percentage, between the MC at 15 per cent and the test MC (below the FSP).

\section{Ultrasonic and stress wave tests}

Stress wave and ultrasound methods for investigating wood are based on the propagation of compression waves through wood. Although the terms are often used interchangeably, stress wave methods are generally low frequency (in the audible range) whereas ultrasonic frequencies are above the audible range.

Both techniques are based on the measurement of the wave propagation speed and attenuation, as stiffness and strength predictors.

The performed tests are based on the time-of-flight measurement to determine wave propagation speed. In these measurement systems, a mechanical or ultrasonic impact is used to impart a wave into a member. Piezoelectric sensors at two points on the member are used to sense passing of the wave. The time it takes for the wave to travel between sensors is measured and used to compute wave propagation speed.

Longer propagation times are generally indicative of the presence of defects, deteriorated wood or wood with lower stiffness or density. Stress wave techniques are also, however, affected by other factors, including MC, wood species and growth-ring orientation.

The general configuration used for strength grading timber is direct transmission along the fibres (Figure 5a); however, this arrangement is often not applicable to timber members in service. Therefore, the indirect transmission across the fibre, determined with the configuration showed in Figure 5b, was tested as an alternative to a set-up having in mind its application to timber elements in situ.

For the measurement of both ultrasonic and stress wave velocities, the data acquisition control unit consisted of a digital oscilloscope, which permitted one to sample and acquire output signal from the probe, and a Pocket PC, which allowed one to display the raw signal, process it and evaluate the attenuation.

Ultrasonic indirect waves' transmission was measured using two piezoelectric transducers with relatively low frequencies $(20 \mathrm{kHz})$ in order to take into account the high wave attenuation typical of wood (Zombori, 2000). In order to conduct local piecewise readings on the longitudinal faces, the transducers were placed at a distance of ca. $500 \mathrm{~mm}$, on the same element face, and readings were made along the entire length of the beams.

Since high-frequency waves attenuate significantly over relatively short distances in wood, an instrumented hammer was used to sense waves' propagation parallel to the grain. In this case the velocity of the longitudinal stress waves was measured after striking
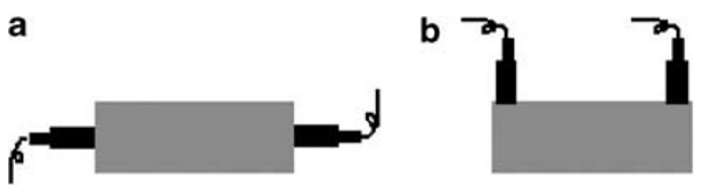

Figure 5: Adopted ultrasonic testing set-ups 
one transversal face of the beam with the hammer and placing the receiving probe on the opposite face. At least two readings per beam were generally made, but a third one was added if the first two readings differed significantly.

Some operational difficulties occurred during testing because of the surface waviness and roughness of timber, in particular as regards the coupling of the piezoelectric transducers to the material surface and the alignment of transducers. A satisfactory physical contact was established by means of applied pressure on the probe and a dry couplant (mastic) between the surfaces. Moreover, wood surfaces were locally processed and finished in order to avoid transducers' lack of alignment.

Presently, different standards emerged to measure the ultrasonic properties of materials with particular reference to ASTM E494 (2001).

For prismatic, homogeneous and isotropic elements and for those with a section width smaller than the stress wavelength, the relation

$$
E_{\text {din }}=\rho V^{2}
$$

gives the (elasto)dynamic $\mathrm{MoE}\left(\mathrm{N} / \mathrm{mm}^{2}\right)$ where $V$ is the propagation velocity of the longitudinal stress waves $(\mathrm{m} / \mathrm{s})$ and $\rho$ is the density of the specimens $\left(\mathrm{kg} / \mathrm{m}^{3}\right)$.

Therefore, density is an important variable that must be measured if a stress wave technique is used to estimate dynamic MoE. Density values, used in Equation (8) to estimate $E_{\text {din }}$, were determined by direct weighting. In practice, when density measurements cannot be effectively taken nondestructively, tabulated values for various species are used.

The difference between the dynamic MoE and the static value $\left(E_{\text {din }} \geqslant 0.90 E_{\text {sta }}\right)$ is explained by the viscous-elastic behaviour of wood. Generally, a linear relation is used (FPL, 1999):

$$
E_{s t a}=\alpha_{1} E_{d i n}+\beta_{1}
$$

where $\alpha_{1}$ and $\beta_{1}$ are constants depending on the material.

In this research, the values of the constants that were used in Equation (9), are $\alpha_{1}=0.741$ and $\beta_{1}=112 \mathrm{Mpa}$ (FPL, 1999).

In order to take into account the MC effect on the ultrasonic stress wave propagation, Sandoz (1993) proposed empirical corrected models (Equations (10) and (11)):

$$
\begin{gathered}
(M C \leqslant 32 \%) V R=V m+29(M C i-12) \\
(M C>32 \%) V R=580+V m+4(M C i-32)
\end{gathered}
$$

with $M C i$ being the test $\mathrm{MC}, V m$ the speed of ultrasound at $\mathrm{MCi}(\mathrm{m} / \mathrm{s}), V R$ the referential speed of ultrasound for $\mathrm{MC}=12$ per cent $(\mathrm{m} / \mathrm{s})$.

In the research presented in this paper, however, stress wave speed was directly determined also for saturated elements.

Although other authors proposed correlations between stress wave velocity and bending strength of wood (ie Sandoz, 1989), in this research the method was used only to estimate, from the dynamic MoE, the stiffness of the material.

\section{Bending tests}

Modulus of elasticity (MoE) can be measured in different loading modes: bending, tension and compression. In all these cases a static load is applied and consequent deformation is measured (or, equivalently, deformation is applied and the needed load is measured). 
Measuring flexural MoE by static-bending techniques has been successfully employed to grade lumber in sawmills by using testing set-ups that approximate simply supported boundary conditions. Boundary conditions on-site may, however, vary considerably in even the simplest structure. Consequently, application of this technique for in situ assessment of timber members has been generally limited to the ND evaluation of the stiffness and buckling of floors or bridges' decks. Its employment for the evaluation of roof rafters or other nonhorizontal structural members is more difficult and rare (ie Abbott and Elcock, 1987).

The assessment of MoE can also be used to nondestructively estimate the bending strength of timber. Indeed, stiffness is the best individual predictor of strength, with a coefficient of correlation $R^{2}$ ranging from 0.51 to 0.73 (Thelandersson and Larsen, 2003). The relation between strength and MoE can, however, be affected by the presence of significant local defects.

In the performed tests, $\mathrm{MoE}$ was directly measured in bending, in accordance with the four-point loading method, and compared with the NDT data.

The EN 408 standard, and analogously the EN 14251 standard for round timber, specifies a four-point bending test, with loads applied at the third points. The distance between supports is 18 times the beam depth. Deflection is measured over a length equal to five times the beam depth centred within the test span (Figure 6).

The two standards permit one to determine the $\operatorname{MoE} E_{m}$, for squared (Equation (12)) and round elements (Equation (13)), respectively:

$$
\begin{gathered}
E_{m}=\frac{a l^{2} \Delta F}{16 I \Delta \omega} \\
E_{m, 0}=\frac{(\Delta M) c^{4}}{6(\Delta \omega) I_{1}}\left[-\frac{1}{(c+l / 2)^{2}}-\frac{D}{2}+\frac{1}{c^{2}}\right]
\end{gathered}
$$

with

$$
c=\frac{l d_{1}}{\left(d_{2}-d_{1}\right)} ; \quad D=\left(\frac{1}{c^{2}}-\frac{1}{(c+l)^{2}}\right)
$$

and $\Delta F$ is the increment of loading on the straight-line portion of the load deformation curve; $l$ the gauge length; $\Delta \omega$ the increment of displacement; $I$ the second moment of area; $a$ the distance between the loading position and the support; $\Delta M$ the increment of bending moment on the straight-line portion of the load-deformation curve; $d_{1}$ the

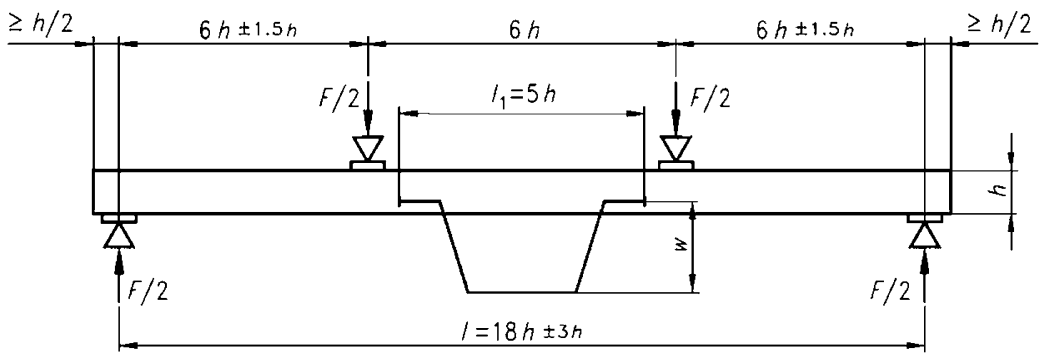

Figure 6: Test arrangement for the determination of the MoE 
smallest apparent diameter along the gauge length; $d_{2}$ the biggest apparent diameter along the gauge length; and $I_{1}$ is the smallest second moment of area along the gauge length.

After assessing MoE, each test specimen was loaded until failure. Destructive bending tests were carried out only on conditioned timber.

In case of timber in structural dimensions, the testing loading condition reproduced the on-site one. In order to evaluate the post-elastic behaviour and collapse mechanism of the material, the mode of failure was established by studying the appearance of the loaddeflection curve and photographs of the broken battens after failure.

A displacement control procedure with an actuator with a load cell of $600 \mathrm{kN}$ (maximum) was adopted. The specimens were instrumented with four linear variable differential transformers (LVDT), with an accuracy of $1 \times 10^{-3} \mathrm{~mm}$. In order to measure contingent asymmetrical deflections of the beam, the LVDT transducers were placed at the mid-span, using two yokes placed on both sides of the cross-section. The resulting measure is obtained averaging the readings on opposite sides. Additionally, transducers were placed at the supports, in order to monitor local effects at these locations. Indeed, during bending tests nonlinear deformation, caused by frictional forces and stress concentration at the loading and supporting points, can occur and produce extra deflection. In order to reduce these local effects, the concentrated forces were applied by placing two steel cylinders under the actuator and interposing between them and the wood surface a rigid steel plate. Shaped wood blocks to fit the round timber were inserted between the test piece and the supports to minimise local indentation.

\section{ANALYSIS OF THE RESULTS}

In the following tables, the results of the grading campaign are shown.

Elements labelled 'A' are timbers in the structural dimensions of larch and spruce (Table 2), while elements labelled ' $\mathrm{R}$ ' and 'Ca' are portions of old beams, respectively, of larch and chestnut, which have been tested at both FSP and EMC.

Table 2: Results of the visual strength grading according to UNI I I 035 and UNI I I I I 9

\begin{tabular}{|c|c|c|}
\hline Element & UNI 11035-2 & UNI 11119 \\
\hline $\mathrm{I}-\mathrm{Ca}$ & $\mathrm{s}$ & I \\
\hline $2-\mathrm{Ca}$ & $\mathrm{s}$ & I \\
\hline $3-\mathrm{Ca}$ & $\mathrm{s}$ & II \\
\hline $4-\mathrm{Ca}$ & $\mathrm{S}$ & I \\
\hline $5-\mathrm{Ca}$ & $\mathrm{s}$ & II \\
\hline $6-\mathrm{Ca}$ & $\mathrm{s}$ & i \\
\hline 7-Ca & $\mathrm{S}$ & I \\
\hline $8-\mathrm{Ca}$ & $S$ & i \\
\hline $9-\mathrm{Ca}$ & $\mathrm{s}$ & II \\
\hline I0-Ca & $S$ & II \\
\hline$I-R$ & Not graded & III \\
\hline $2-R$ & Not graded & III \\
\hline $3-R$ & Not graded & III \\
\hline I-R_4 & S3 & III \\
\hline $2-R-5$ & S2 & ॥ \\
\hline 3-R_4 & Not graded & Not graded \\
\hline $2-A$ & S3 & III \\
\hline $3-A$ & S3 & III \\
\hline $4-A$ & S2 & $\|$ \\
\hline $6-A$ & S2 & II \\
\hline $9-A$ & S3 & II \\
\hline II-A & S3 & II \\
\hline
\end{tabular}


In Table 2 the tested elements and the corresponding strength classes, assigned according to UNI 11035 and UNI 11119 standards, are listed.

According to UNI 11035, two beams of the refuge (elements A-3 and A-5, Table 3) and four portions of larch beams (R1, R2, R3, 3R_4) could not be graded because of the presence of wane exceeding the limits set by the code. Criteria in UNI 11119 permit one to grade one of the exceeding wayned beams (element A-3), considering the actual stress distribution along the element and the consequent incidence of defects.

Values of MoE obtained from visual strength-grading and NDT tests are summarised in Tables 3 and 4 for conditioned and saturated wood, respectively. The NDT data are

Table 3: Visual grading and NDT MoE values compared with values from bending tests (specimens at EMC)

\begin{tabular}{|c|c|c|c|c|c|c|c|c|c|c|}
\hline \multirow[b]{3}{*}{ Element $\mathbf{N}$. } & \multirow[b]{3}{*}{ MC \% } & \multicolumn{9}{|l|}{ MoE } \\
\hline & & \multirow{2}{*}{$\begin{array}{l}\text { Bending test } \\
(\mathrm{MPa})\end{array}$} & \multicolumn{2}{|c|}{ UNI 11035} & \multicolumn{2}{|c|}{ UNI 11119} & \multicolumn{2}{|c|}{ Hardness test } & \multicolumn{2}{|c|}{ Ultrasound test } \\
\hline & & & (MPa) & $\Delta \%$ & (MPa) & $\Delta \%$ & (MPa) & $\Delta \%$ & (MPa) & $\Delta \%$ \\
\hline $\mathrm{I}-\mathrm{Ca}$ & 17 & 9,671 & | |,880 & 23 & 9,200 & -5 & 12,235 & 27 & I I,575 & 20 \\
\hline $2-\mathrm{Ca}$ & 15 & 11,167 & 12,320 & 10 & 9,600 & -14 & 12,813 & 15 & 12,720 & 14 \\
\hline $3-\mathrm{Ca}$ & 16 & $13, \mid 47$ & 12,100 & -8 & 8,460 & -36 & 10,942 & -17 & 14,128 & 7 \\
\hline $4-\mathrm{Ca}$ & 13.5 & 13,548 & 12,540 & -7 & 9,800 & -28 & II,734 & -13 & 14,475 & 7 \\
\hline $5-\mathrm{Ca}$ & 13 & 12,584 & 12,540 & 0 & 8,820 & -30 & $|0,7| \mid$ & -15 & 14,268 & 13 \\
\hline 6-Ca & 13 & $|2,29|$ & 12,320 & 0 & 9,600 & -22 & 12,594 & 2 & 13,882 & 13 \\
\hline 7-Ca & 13 & 13,303 & 12,540 & -6 & 9,800 & -26 & 12,627 & -5 & 14,092 & 6 \\
\hline $8-\mathrm{Ca}$ & 13.5 & 12,275 & 12,320 & 0 & 9,600 & -22 & 12,624 & 3 & 14,396 & 17 \\
\hline $9-\mathrm{Ca}$ & 13.5 & 11,630 & 12,100 & 4 & 8,460 & -27 & 11,249 & -3 & 14,975 & 29 \\
\hline I0-Ca & 14 & 9,392 & 12,100 & 29 & 8,460 & 10 & 10,360 & 10 & $|3,56|$ & 44 \\
\hline I-R_4 & 16 & 12,312 & 12,400 & I & 12,420 & 1 & 12,462 & I & 13,082 & 6 \\
\hline 2-R_5 & 15 & $|4,34|$ & 13,200 & -8 & 13,630 & -5 & 14,599 & 2 & 13,866 & -3 \\
\hline 3-R_4 & 15 & 12,026 & - & - & - & - & 10,824 & -10 & 13,374 & II \\
\hline $2-A$ & 9 & 17,257 & I I,500 & -19 & 14,310 & -17 & 11,899 & -31 & 11,628 & -33 \\
\hline $3-A$ & 10 & $|3,22|$ & - & -14 & 10,920 & -17 & I I,792 & -11 & II,354 & -14 \\
\hline $4 \mathrm{~A}$ & 10 & 18,177 & 10,500 & -31 & 10,920 & -40 & $13,3 \mid 2$ & -27 & 9,880 & -46 \\
\hline $6-A$ & 10 & 10,563 & 10,500 & 19 & 11,960 & 13 & 12,432 & 18 & 10,244 & -3 \\
\hline $9-A$ & 10 & 15,016 & 9,500 & -24 & 10,920 & -27 & 12,510 & -17 & 9,557 & -36 \\
\hline$I I-A$ & 8 & 9,994 & I I,500 & 43 & 15,370 & 54 & 13,548 & 36 & 12,380 & 24 \\
\hline
\end{tabular}

Table 4: Visual grading and NDT MoE values compared with values from bending tests (specimens at FSP)

\begin{tabular}{|c|c|c|c|c|c|c|c|c|c|c|}
\hline \multirow[b]{3}{*}{ Element $\mathbf{N}$. } & \multirow[b]{3}{*}{ MC \% } & \multicolumn{9}{|l|}{ MoE } \\
\hline & & \multirow{2}{*}{$\begin{array}{l}\text { Bending test } \\
(\mathrm{MPa})\end{array}$} & \multicolumn{2}{|c|}{ UNI 11035} & \multicolumn{2}{|c|}{ UNI 11119} & \multicolumn{2}{|c|}{ Hardness test } & \multicolumn{2}{|c|}{ Ultrasound test } \\
\hline & & & $(\mathrm{MPa})$ & $\Delta \%$ & $(\mathrm{MPa})$ & $\Delta \%$ & (MPa) & $\Delta \%$ & $(\mathrm{MPa})$ & $\Delta \%$ \\
\hline $\mathrm{I}-\mathrm{Ca}$ & 57 & 6,294 & 9,900 & 61 & 7,400 & 20 & 8,340 & 25 & 10,816 & 42 \\
\hline $2-\mathrm{Ca}$ & 49.5 & 8,402 & 9,900 & 18 & 7,400 & -12 & 8,940 & 6 & 11,232 & 25 \\
\hline $3-\mathrm{Ca}$ & 48 & 10,193 & 9,900 & -3 & 6,660 & -35 & 7,701 & -32 & 13,033 & 22 \\
\hline $4-\mathrm{Ca}$ & 45.5 & 10,667 & 9,900 & -7 & 7,400 & -31 & 8,752 & -22 & I I,792 & 10 \\
\hline $5-\mathrm{Ca}$ & 54.5 & 9,566 & 9,900 & 3 & 6,660 & -30 & 7,339 & -30 & 11,296 & 15 \\
\hline $6-\mathrm{Ca}$ & 52.5 & 9,285 & 9,900 & 7 & 7,400 & -20 & 8,584 & -8 & 10,825 & 14 \\
\hline $7-\mathrm{Ca}$ & 52 & 10,224 & 9,900 & -3 & 7,400 & -28 & 8,313 & -23 & 11,805 & 13 \\
\hline $8-\mathrm{Ca}$ & 44.5 & 9,313 & 9,900 & 6 & 7,400 & -21 & 9,271 & 0 & 10,887 & 14 \\
\hline $9-\mathrm{Ca}$ & 41.5 & 8,859 & 9,900 & 12 & 6,660 & -25 & 8,412 & -5 & 11,957 & 26 \\
\hline I0-Ca & 55 & 6,378 & 9,900 & 55 & 6,660 & 4 & 6,453 & I & 9,700 & 34 \\
\hline I-R 4 & 29 & 8,074 & 9,660 & 20 & 9,180 & 14 & 8,545 & 6 & $|0,53|$ & 23 \\
\hline $2-R \_5$ & 29 & 9,549 & 10,080 & 6 & 9,860 & 3 & 10,963 & 13 & 9,720 & 2 \\
\hline 3-R_4 & 29 & 7,447 & - & - & - & - & 5,982 & -24 & 10,040 & 26 \\
\hline
\end{tabular}


compared with the true bending stiffness, determined with four-point bending tests. The difference between the predicted values and the bending property is also shown.

For conditioned woods, the mean differences in percentage, between the MoE obtained from static bending tests and from visual strength-grading, are -0.7 and -2 for the tested softwood elements, 4.5 and -20 for chestnut, applying criteria of UNI 11035 and UNI 11119 , respectively.

For saturated specimens, the mean percentage error is 15 and -13 , respectively, for the two visual grading criteria.

This means that results of visual grading generally underestimate the actual stiffness of the material. Properties derived from visual grading are obviously fifth percentile values; this explains why they are generally lower than the values experimentally obtained for each beam. UNI 11119 is more conservative because the grade properties attributed to the in-service classes were not determined through an extensive experimental campaign on existing timber structures, but rather were simply derived from the values obtained for new timber.

The mean differences in percentage between the MoE obtained from bending tests and the adopted NDT methods are -1.8 for the hardness test and 4.01 for the ultrasound test for conditioned wood, and -7 and 21 for saturated wood, respectively.

The error of the visual grading methods in predicting the stiffness of elements in structural size is -4.3 per cent and -5.7 per cent (in absolute value 25 per cent and 28 per cent) if UNI 11035 and UNI 11119 standards are applied, respectively. For the same group of elements, the mean error of the hardness test is -5.3 per cent (absolute value 23 per cent) and of the ultrasound test is 3.3 per cent (absolute value 26 per cent). The error values in predicting the stiffness of timbers in structural dimension can be explained with the high presence of inhomogeneities. The hardness test is carried out on clear wood portions, and then a reduction factor $\delta$ (Equation (6)) is applied in order to take into account the defectiveness of the material. The error estimated for the hardness test can be attributed to the partial subjectivity in judging the severity of defects and, consequently, in applying the factor $\delta$.

The true strength of the timber elements, determined through destructive bending tests, has been compared with strength values predicted by applying UNI 11035 and UNI 11119 criteria. The results are shown in Table 5. The mean errors, in percentage, are -50 and -61 , respectively. Therefore, generally, visual grading methods underestimate the true strength.

In particular, as regards timber in structural dimensions, the strength value of element 2-A, resulting from the bending test, deeply diverges from the one referring to the element grading; indeed even if the beam was graded to the lowest strength class, it exhibited the highest strength among the tested elements. Conversely, element 7-A failed at 17 vs $29 \mathrm{Mpa}$ predicted through visual grading. In this case, the overestimate depends on the presence of not visible defects, indeed the failure initiated where a hidden knot at the tensile side was located.

As further treatment for the gathered data, statistical regression analyses between parameters obtained from all individual grading methods and the bending properties resulting from the static tests were made.

The closer data are grouped around the regression line and the lower the variability, the more successful an NDT parameter is at predicting performance.

The regression analysis yields the so-called 'coefficient of correlation', $R$. Its square is called 'coefficient of determination', $R^{2}$. The value of $R^{2}$ indicates the portion of the total variation of the predicted variable that is explained by the predictor (Figures 7-17). 
Table 5: Visual grading MoR values compared with values from bending tests (specimens at EMC)

\begin{tabular}{|c|c|c|c|c|c|}
\hline \multirow[b]{2}{*}{ Element } & \multirow{2}{*}{$\begin{array}{l}\text { Bending test } \\
f_{\mathrm{m}}(\mathrm{MPa})\end{array}$} & \multirow{2}{*}{$\begin{array}{l}\text { UNI } 11035 \\
f_{\mathrm{k}}(\mathrm{MPa})\end{array}$} & \multicolumn{3}{|c|}{ UNI 11119} \\
\hline & & & $\Delta \%$ & $f_{\mathrm{k}}(\mathrm{MPa})$ & $\Delta \%$ \\
\hline I-Ca_I & 46 & 25 & -46 & 21 & -54 \\
\hline I-Ca_2 & 46 & 25 & -46 & 21 & -55 \\
\hline I-Ca_3 & 46 & 25 & -46 & 21 & -54 \\
\hline 2-Ca_I & 43 & 25 & $-4 I$ & 21 & -51 \\
\hline 2-Ca_2 & 66 & 25 & -62 & 21 & -68 \\
\hline 2-Ca_3 & 56 & 25 & -55 & 21 & -62 \\
\hline 3-Ca_l & 54 & 25 & -54 & 18 & -67 \\
\hline 3-Ca_2 & 50 & 25 & -50 & 18 & -64 \\
\hline 3-Ca_3 & 43 & 25 & -42 & 18 & -58 \\
\hline 3-Ca_4 & 74 & 25 & -66 & 18 & -76 \\
\hline $4-\mathrm{Ca}^{-}$ & 55 & 25 & -55 & 21 & -62 \\
\hline $5-\mathrm{Ca}$ & 54 & 25 & -54 & 18 & -67 \\
\hline 6-Ca & 52 & 25 & -52 & 21 & -60 \\
\hline 7-Ca & 57 & 25 & -56 & 21 & -63 \\
\hline $8-\mathrm{Ca}$ & 58 & 25 & -57 & 21 & -64 \\
\hline 9-Ca & 51 & 25 & -51 & 18 & -65 \\
\hline I0-Ca & 51 & 25 & -18 & 18 & $-4 I$ \\
\hline I-R_I & 53 & 45 & -15 & 29 & -45 \\
\hline I-R_2 & 64 & 45 & -30 & 29 & -55 \\
\hline I-R_3 & 15 & - & - & - & - \\
\hline I-R_4 & 44 & 29 & -34 & 20 & -55 \\
\hline 2-R_I & 30 & 29 & -5 & 19 & -37 \\
\hline 2-R_2 & 55 & 46 & -16 & 29 & -47 \\
\hline 2-R_3 & 88 & 46 & -48 & 29 & -67 \\
\hline 2-R_4 & 57 & 46 & -20 & 29 & -49 \\
\hline 2-R_5 & 58 & 35 & -40 & 25 & -57 \\
\hline 3-R_I & 35 & 29 & -16 & 20 & -42 \\
\hline 3-R_2 & 30 & 29 & -4 & 20 & -34 \\
\hline 3-R_3 & 17 & 29 & 74 & 20 & 20 \\
\hline 3-R_4 & 27 & - & - & - & - \\
\hline $2-A$ & 64 & 26 & -51 & 27 & -61 \\
\hline $3-A$ & 49 & 28 & -43 & 27 & -45 \\
\hline $4-A$ & 49 & 28 & -43 & 27 & -45 \\
\hline 6-A & 35 & 28 & -19 & 27 & -22 \\
\hline 7-A & 22 & 39 & 74 & 32 & 42 \\
\hline 8-A & 35 & 35 & -1 & 32 & -9 \\
\hline 9-A & 27 & 28 & 4 & 22 & -18 \\
\hline II-A & 41 & 39 & -4 & 32 & -21 \\
\hline
\end{tabular}

Correlation coefficients can range from -1 to 1 . A correlation coefficient nearing 1 suggests a strong positive relationship. A correlation coefficient of zero reveals that no relationship exists, positive or negative.

The ultrasound test exhibits a negative correlation with the MoE of the conditioned specimens, measured by means of four-point bending tests $(R=-0.3)$. Nevertheless, the higher correlation, among all the grading methods, is given by the ultrasound test for saturated specimens $(R=0.6)$, whereas the other methods show a very poor correlation (UNI 11119: $R=0.3$ at EMC, $R=0.2$ at FSP; UNI 11035: $R=-0.3$ at EMC, $R=0.04$ at FSP; hardness test: $R=0.2$ at EMC, $R=0.3)$. For softwood-conditioned specimens only, the hardness test exhibits a positive correlation $(R=0.6)$.

The coefficient of correlation between true strength and strength predicted by visual grading is higher for UNI 11035 ( $R=0.6$ for softwoods, $R=0.2$ for all the specimens) than for UNI 11119 ( $R=0.4$ for softwoods, $R=0.01$ for all the specimens).

Finally, it is interesting to compare MoE values and bending strengths $f_{m}$, both experimentally obtained. Linear regression analysis was carried out for timber in 


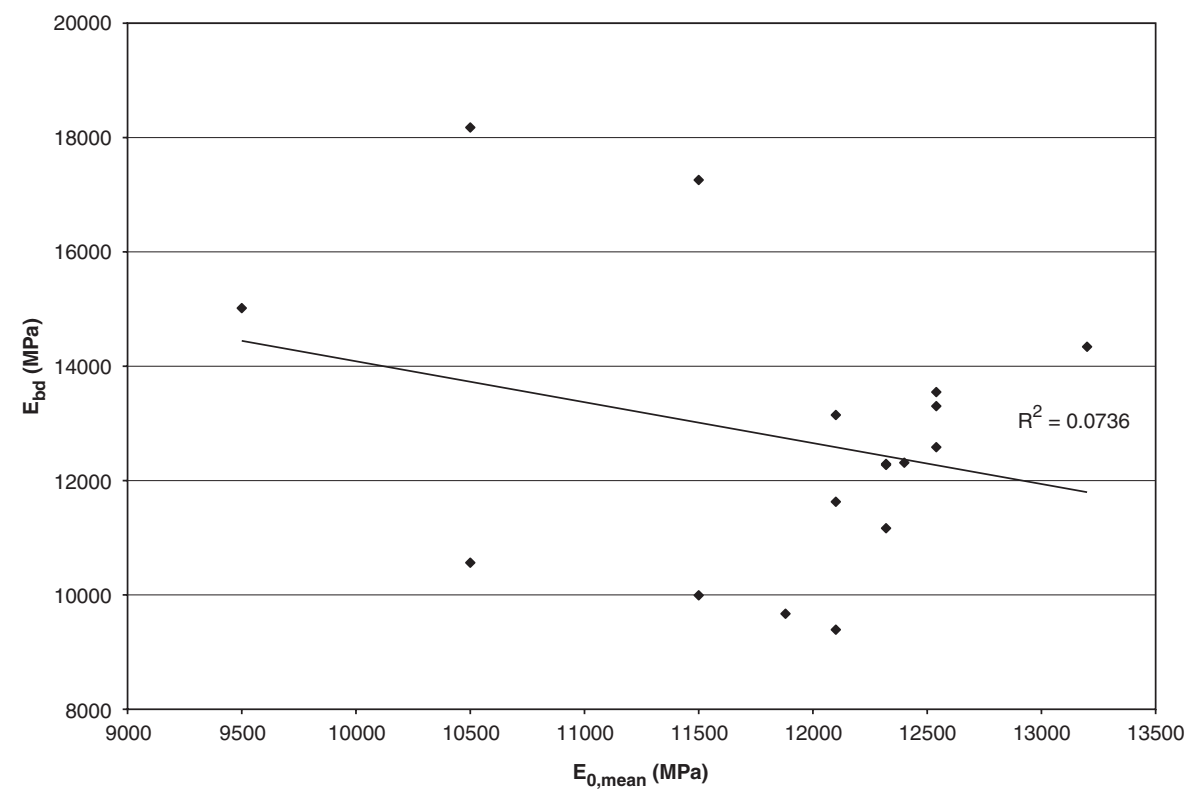

Figure 7: Static bending $\mathrm{MoE}(\mathrm{MPa}), E_{b d}$ vs $E_{0, \text { mean }} \mathrm{MoE}$ from UNI I 035

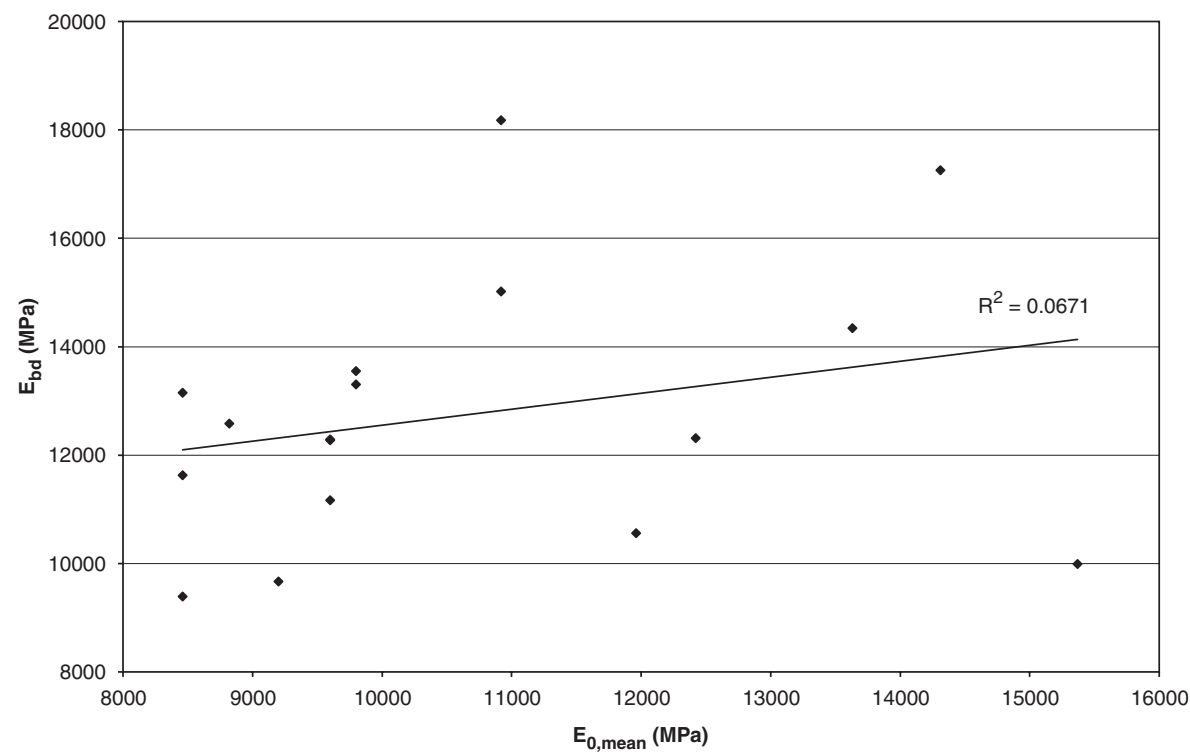

Figure 8: Static bending $\mathrm{MoE}(\mathrm{MPa}), E_{b d}$ vs $E_{0, \text { mean }} \mathrm{MoE}$ from UNI III I9

structural size, and results reveal a modest positive correlation between stiffness and strength ( $R=0.5$ for softwoods, $R=0.1$ for the whole test material). In particular, two cases show deep discrepancies between the two properties: element 9-A has one of the highest MoEs $(15,016 \mathrm{Mpa})$ but one of the lowest bending strengths $\left(f_{m}=27 \mathrm{Mpa}\right)$.

Conversely, the element with the lowest MoE (element 11-A, MoE=9994 Mpa) exhibited one of the highest bending strengths $\left(f_{m}=41 \mathrm{Mpa}\right)$. 


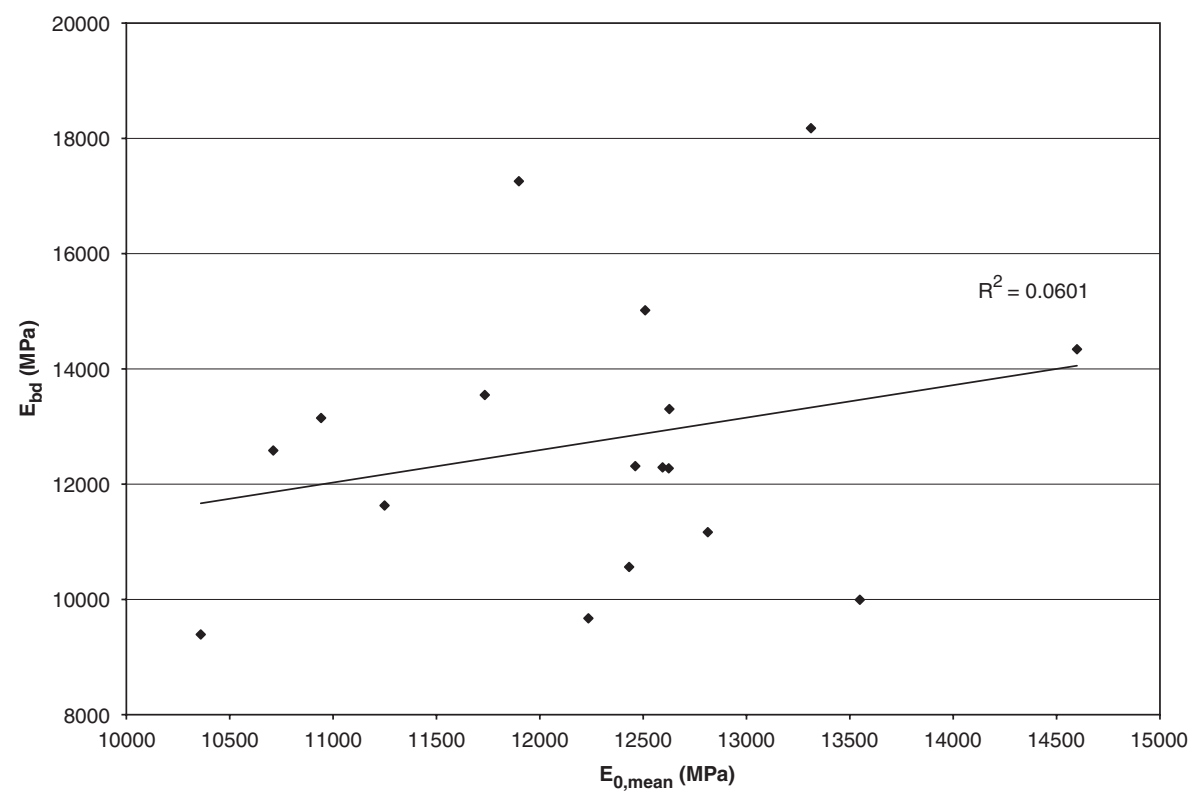

Figure 9: Static bending $\mathrm{MoE}(\mathrm{MPa}), E_{b d}$ vs $E_{0, \text { mean }}$ MoE from hardness test (Piazza and Turrini)

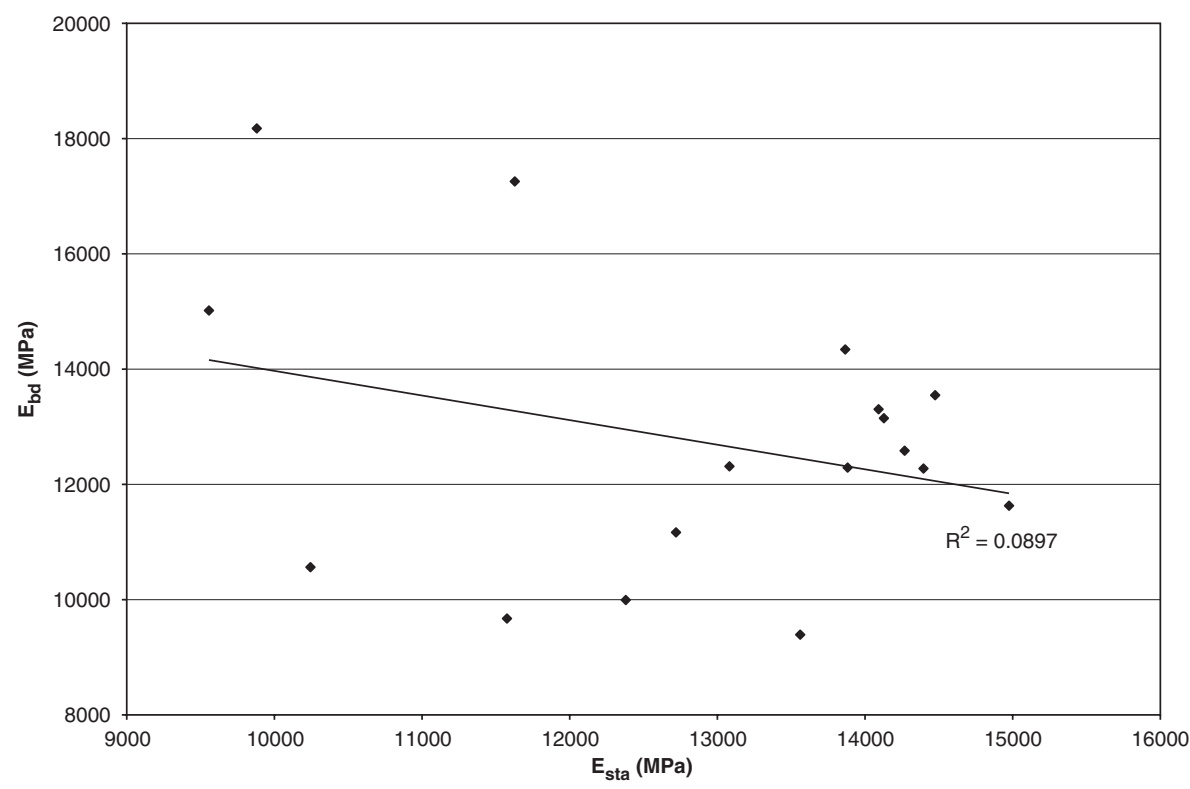

Figure 10: Static bending $\mathrm{MoE}(\mathrm{MPa}), E_{b d}$ vs $E_{\text {sta }}$ static MoE from ultrasonic tests

Complementary to the two main grading properties, also density parameters, obtained by both direct methods (weighting) and indirect methods (visual grading, NDT), have been compared.

Density values obtained by direct weighting have been compared with the mean and characteristic values resulting from grading (Table 6).

For both Pilodyn and Resistograph tests, a regression analysis has been performed in order to evaluate the correlation between the found NDT parameters and density. In 


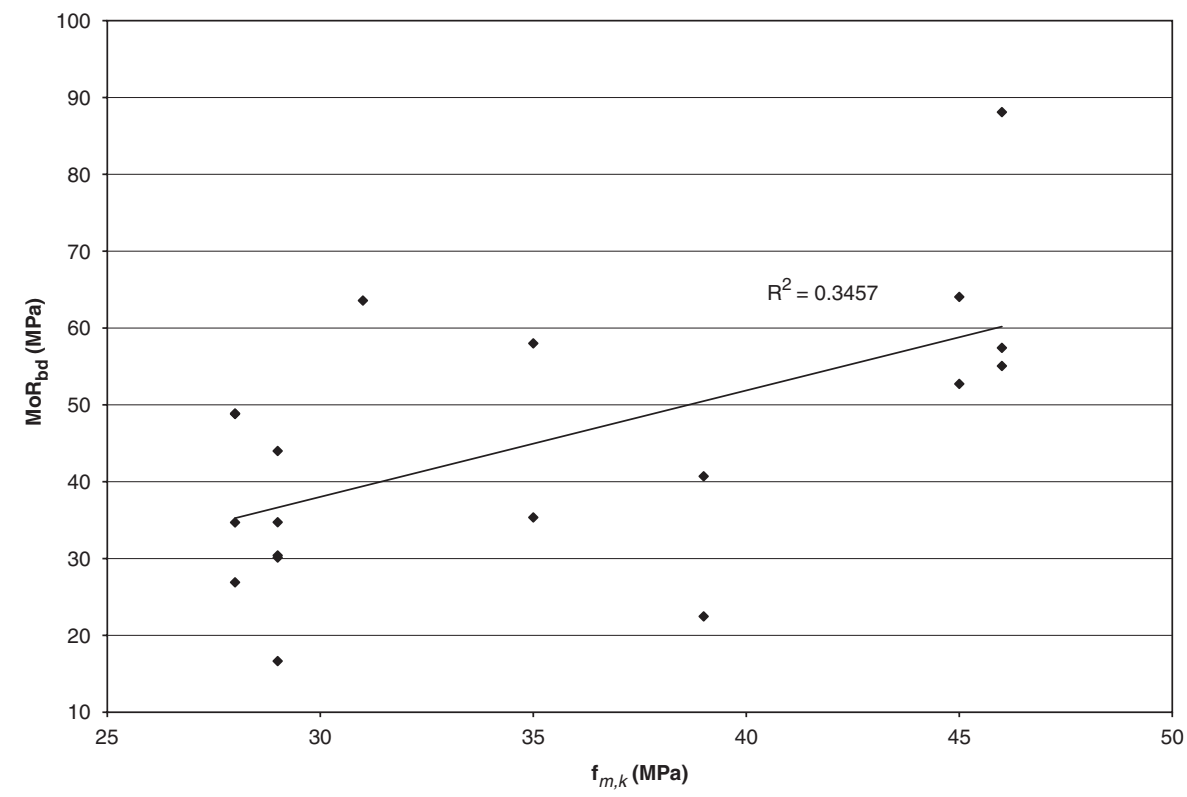

Figure I I: Static bending strength vs $f_{m, k}$ characteristic bending strength (MPa) from UNI I I 035

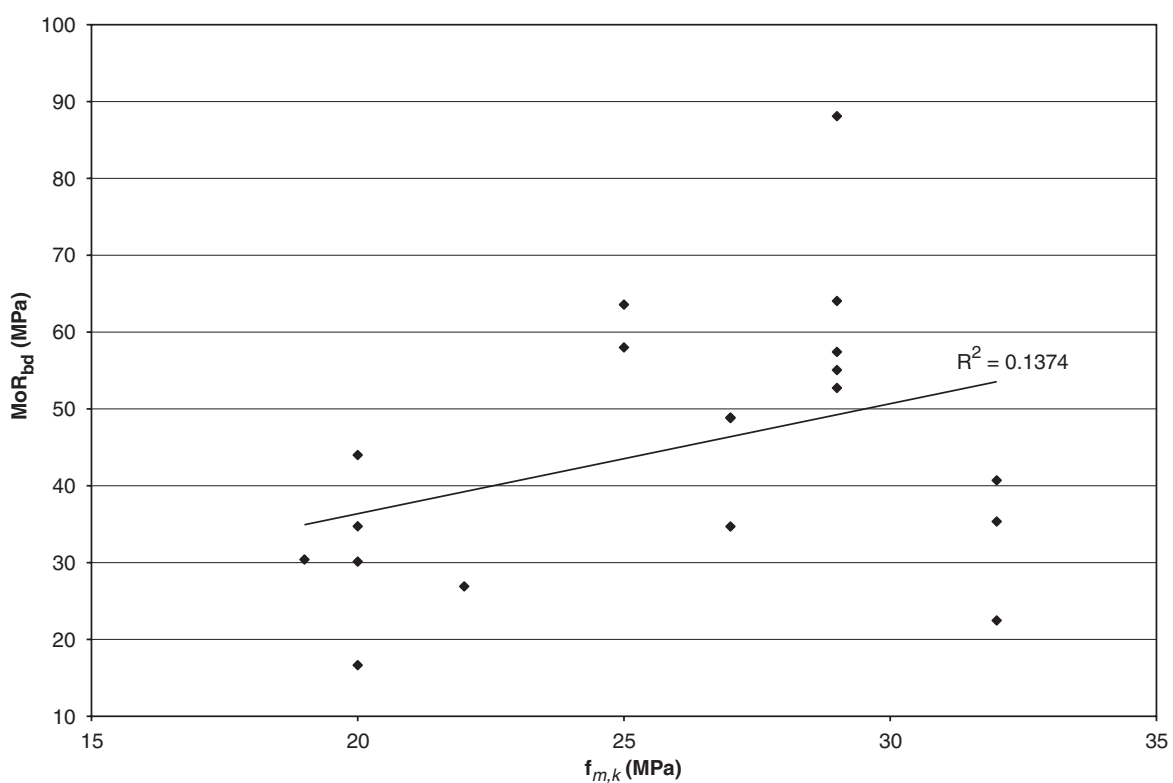

Figure 12: Static bending strength vs $f_{m, k}$ characteristic bending strength (MPa) (derived from UNI IIII9)

particular, the mean values derived from Pilodyn tests (depth of penetration in $\mathrm{mm}$ ) and Resistographic tests (the integral of the drill resistance function divided by the penetration length) have been used as NDT parameters.

For both NDT methods no correlation has been found, either positive or negative (Figures 13 and 14). 


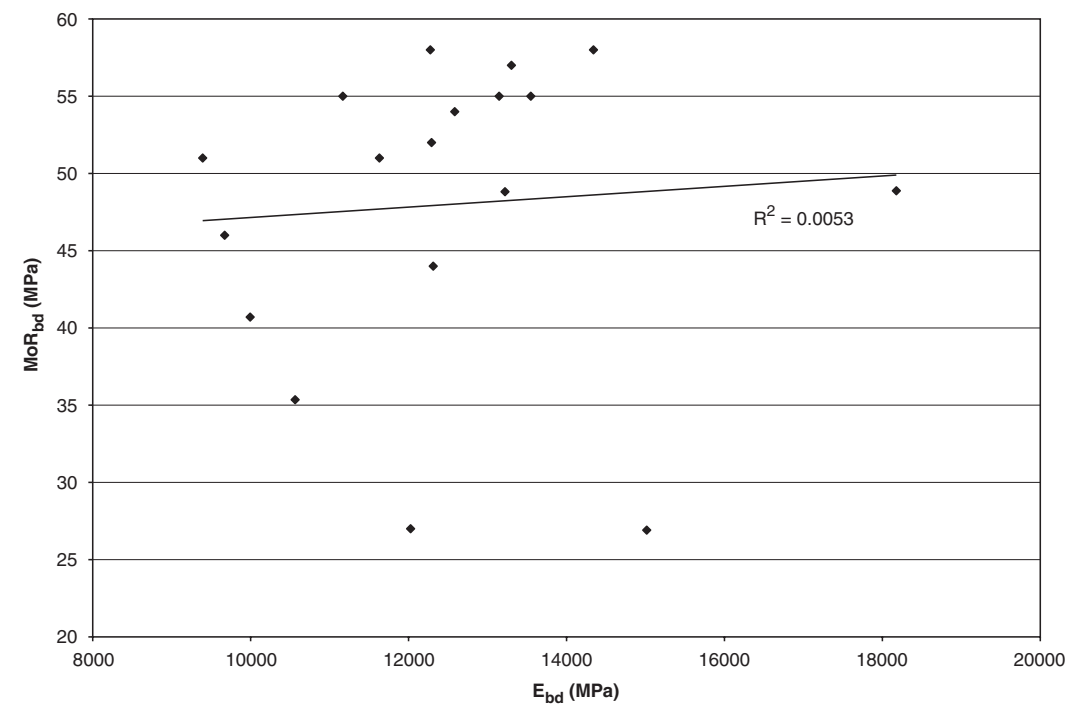

Figure 13: Static bending $\mathrm{MoE}(\mathrm{MPa}), E_{b d}$ vs static bending strength (MPa)

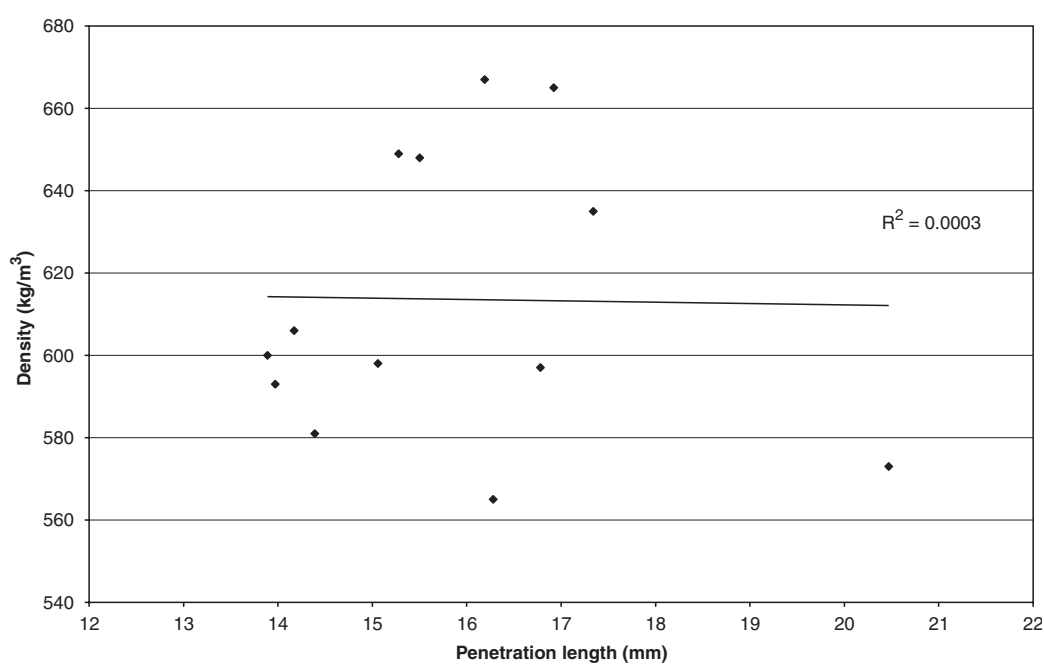

Figure 14: Density values $\left(\mathrm{kg} / \mathrm{m}^{3}\right)$ vs Pilodyn data $(\mathrm{mm})$

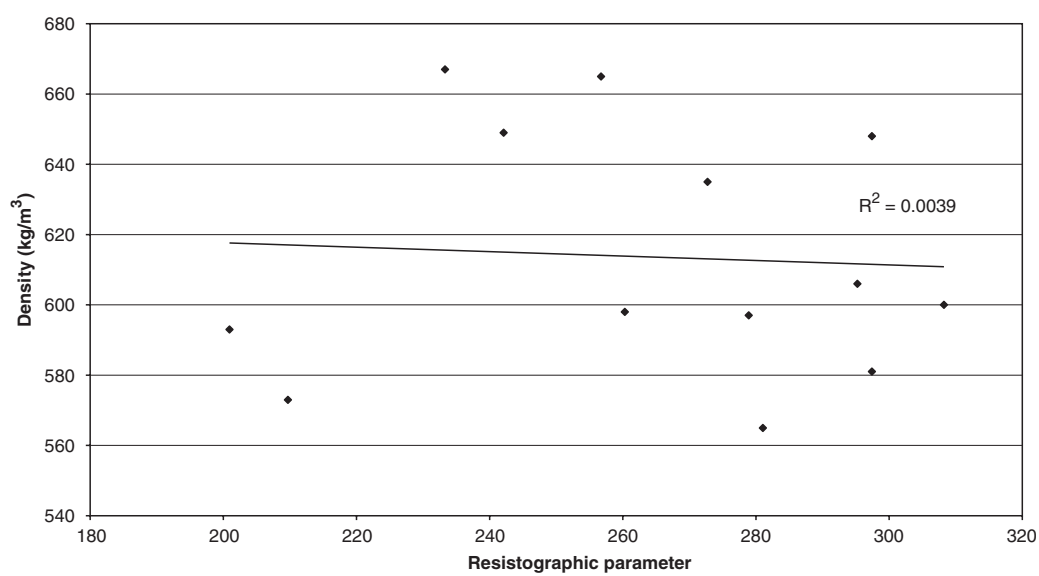

Figure 15: Density values $\left(\mathrm{kg} / \mathrm{m}^{3}\right)$ vs Resistograph data 


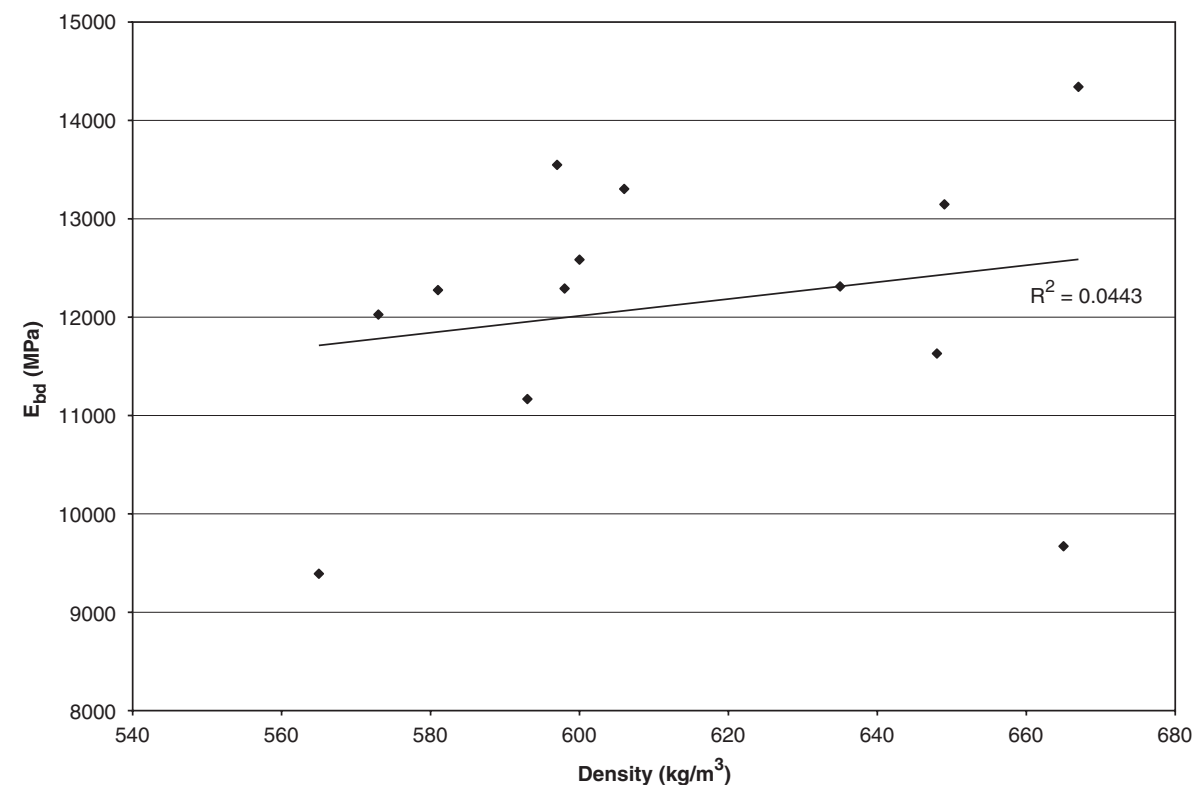

Figure 16: Static bending $\mathrm{MoE}(\mathrm{MPa}), E_{b d}$ vs density $\left(\mathrm{kg} / \mathrm{m}^{3}\right)$

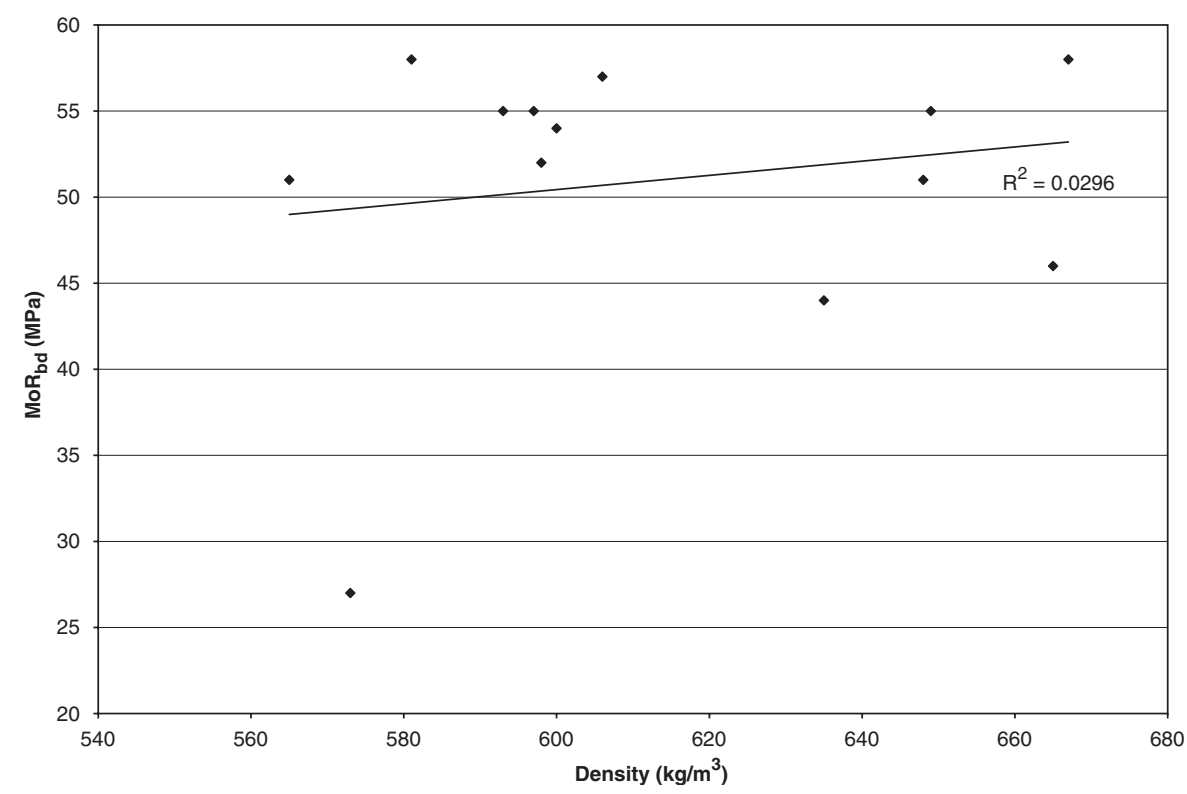

Figure 17: Static bending strength $(\mathrm{MPa})$ vs density $\left(\mathrm{kg} / \mathrm{m}^{3}\right)$

Density has also been treated as a grade-determining property. For this purpose, analogously as it was done for $\mathrm{MoE}$, a linear regression analysis was carried out between the experimental values of density, obtained by direct weighting, and the MoE and MoR values resulting from the bending tests (Figures 15 and 16). A higher correlation of density with the MoE than with the MoR was expected. Both $R$ values are, however, very low $(R=0.21$ for MoE, $R=0.17$ for MoR), and the former is just slightly higher than the latter. 
Table 6: Comparison of density with visual grading and NDT values (specimens at EMC)

\begin{tabular}{|c|c|c|c|c|c|c|c|}
\hline \multirow[t]{2}{*}{ Element } & \multirow{2}{*}{$\begin{array}{l}\rho \\
\mathrm{kg} / \mathrm{m}^{3}\end{array}$} & \multicolumn{4}{|c|}{ UNI 11035} & \multirow{2}{*}{$\begin{array}{l}\text { Pilodyn } \\
\text { mm }\end{array}$} & \multirow[t]{2}{*}{ Resistograph } \\
\hline & & $\rho_{\mathrm{k}}$ & $\Delta \%$ & $\rho_{\mathrm{m}}$ & $\Delta \%$ & & \\
\hline $\mathrm{I}-\mathrm{Ca}$ & 665 & 465 & -43 & 550 & -21 & 16.92 & 256.72 \\
\hline $2-\mathrm{Ca}$ & 593 & 465 & -28 & 550 & -8 & 13.97 & 200.91 \\
\hline $3-\mathrm{Ca}$ & 649 & 465 & -40 & 550 & -18 & 15.28 & 242.11 \\
\hline $4-\mathrm{Ca}$ & 597 & 465 & -28 & 550 & -9 & 16.78 & 278.90 \\
\hline $5-\mathrm{Ca}$ & 600 & 465 & -29 & 550 & -9 & 13.89 & 308.22 \\
\hline $6-\mathrm{Ca}$ & 598 & 465 & -29 & 550 & -9 & 15.06 & 260.31 \\
\hline $7-\mathrm{Ca}$ & 606 & 465 & -30 & 550 & -10 & 14.17 & 295.24 \\
\hline $8-\mathrm{Ca}$ & 581 & 465 & -25 & 550 & -6 & 14.39 & 297.40 \\
\hline 9-Ca & 648 & 465 & -39 & 550 & -18 & 15.5 & 297.40 \\
\hline I0-Ca & 565 & 465 & -22 & 550 & -3 & 16.28 & 281.03 \\
\hline $\mathrm{I}-\mathrm{R}$ & 635 & 550 & -15 & 600 & -6 & 17.34 & 272.71 \\
\hline $2-R$ & 667 & 550 & -21 & 600 & -11 & 16.19 & 233.29 \\
\hline $3-R$ & 573 & 550 & -4 & 600 & 5 & 20.47 & 209.71 \\
\hline
\end{tabular}

\section{CONCLUSIONS}

The reported test results are doubtful and ambiguous, and the discrepancies in the tests highlight the complexity of characterising material in old timber structures.

From the statistical analysis, none of the adopted grading methods exhibits an adequate correlation with the analysed parameter. Despite the limits of the research (limited number and types of specimens, measurements errors, etc) however, some important conclusions can be drawn.

Dedicated on-site visual grading criteria must be established, taking into account the incidence of the different defects on traditional timber elements' strength. The different dimensions of traditional timber elements with respect to actual sawmill products must be considered.

'Technological' characteristics such as wane cannot be accounted for downgrading defects in the case of old timber beams. The presence of waney edges has to be considered just as influencing the effective resistant cross-sectional area.

Knots are by far the most important downgrading defects. The incidence of knots within the element is quite significant in the case of thick elements, like beams. The actual methods consider the superficial incidence of the knots, by-passing the difficulties in measuring the actual size, shape and direction of the internal knot cone, required in the KAR. Conversely, KAR, if adopted, does not permit one to estimate the influence of spike knots.

A knowledge of external defects combined with internal interpretation to recreate internal defects structures would permit a more reliable grading process. Of course, none of the visual criteria is able to predict the influence of not visible defects. While diffuse internal defects can be detected by means of NDT, it is more difficult to estimate the presence of punctual defects.

'Global' ND methods, such as ultrasound and stress wave methods, are useful to have information on the entire element.

In particular, a good correlation with the mean values of flexural MoE can be obtained with direct longitudinal transmission methods; unfortunately, this test set-up is often difficult to apply on-site. Data of the ultrasound and stress wave methods reported in this paper are mean values obtained from both indirect and direct transmission. The former test set-up is more feasible, in case of on-site analysis, but gives uncertain results, especially for timber elements with severe superficial defects. 
ND 'local' methods permit one to have local information about the wood limited to a portion of material, with a penetration of some millimetres (Pilodyn) or of the entire element depth (Resistograph). Therefore, in order to obtain a sufficiently reliable mean value of the investigated parameter, a large number of tests along the whole element must be carried out.

Pilodyn data obtained averaging results on the whole element are not able to predict global parameters (ie mean density). On the contrary, single Pilodyn data permit one to map the condition of the surface decay and highlight the regions of the element that need further investigation, with more sophisticated ND methods.

A correlation between Resistograph data and density can be found only when the element shows similar Resistographic curves in the different tested sections. This means that the method is not able to predict density (or related mechanical properties), in case of elements with local macroscopic dishomogeneities (ie checks, local decay). The combined Resistographic profiles in a section, however, permit one to assess the extension of the decayed areas and reconstruct the effective residual section.

In general, for both NDT methods and visual grading criteria, the correlation between the investigated and the test parameter is lower for MCs other than for the EMC. Therefore, a wider error range must be expected when grading timber elements with significant moisture gradients than when grading conditioned elements.

For the chestnut elements, all the adopted grading methods showed lower correlations than for the two tested softwood species. This is because grading criteria and NDT methods were conceived and tested especially for species that are more widely used in modern constructions. Nevertheless, the use of hardwood species, such as chestnut, is common in traditional structures, especially in the Mediterranean area. For this reason, the grading criteria referred to the hardwood species must be improved in order to permit a more reliable characterisation of the wood on-site.

Finally, because visual grading alone, as well as the use of a single ND method, cannot supply sufficiently correct information on element behaviour, different methods have to be combined. The obtained data have to be critically analysed in order to acquire information about the mechanical properties of on-site members and set up reliable engineering numerical models for the structural analysis.

\section{Acknowledgements}

This project was partly financed through the research project activities of the Italian Department of University and Research (Research Project 2006089730). We acknowledge the precious help of the President of 'Associazione ai Caduti dell'Adamello' and of Dino Leonesi, for the authorisation for the utilisation of old timber elements of the Refuge; Maria Ivana Pezzo, Stefano Marconi, Maurizio Battisti of Museo Civico di Rovereto and the director Franco Finotti, for the dendrochronological analysis; and students Alberto Zamatteo Gerosa and Alessandro Foresti.

\section{Note}

1 In Italy the first code for the inspection of timber on-site was issued in 2004 (UNI 11119:2004).

\section{References}

Abbott, A.R. and Elcock, G. (1987) 'Pole testing in the European context', Proceedings of the 6th Symposium on Nondestructive Testing of Wood; 1987 14-16th September, 1987; Washington State University, Pullman, WA, pp. 277-302.

AFNOR B 52-001-4 (1991) Règies d'utilisation du bois dans les constructions Partie 4: Classement visuel pour emploi en structure pour les principales essences résineuses et feuillues, Association Française de Normalisation, La Plaine Saint-Denis Cedex, France. 
ASTM D1990-00 (2002) e1. Standard Practice for Establishing Allowable Properties for Visually-Graded Dimension Lumber from In-Grade Tests of Full-Size Specimens, ASTM International, West Conshohocken, PA, www.astm.org.

ASTM D245-06 (2006) Standard Practice for Establishing Structural Grades and Related Allowable Properties for Visually Graded Lumber, ASTM International, West Conshohocken, PA, www.astm.org.

ASTM D4442-92 (2003) Standard Test Methods for Direct Moisture Content Measurement of Wood and Wood-Base Materials, ASTM International, West Conshohocken, PA, www.astm.org.

ASTM E494 (2001) Practice for Measuring Ultrasonic Velocity in Materials ASTM International, West Conshohocken, PA, www.astm.org.

Baldassino, N., Piazza, M. and Zanon, P. (1996) 'In situ evaluation of the mechanical properties of timber structural elements', 10th International Symposium on Nondestructive Testing of Wood; Lausanne, Switzerland, 26-28th August, 1996.

Barrett, J.D. and Fewell, A.R. (1990) Size Factors for the Bending and Tension Strength of Structural Timber. CIB/W 18 A-Timber structures, Paper 23-10-3, Lisbon, Portugal.

Bodig, J. and Jayne, B.A. (1982) Mechanics of Wood and Wood Composites, Van Nostrand Reinhold, New York, NY. Brazier, J.D. (1954) The Influence of Grain Direction on Some of the Strength Properties of Canadian Grown Sitka Spruce. Forest Products Research Laboratory, Int. Report.

BS 4978 (1996) Sections 1 and 2. Softwood Grades for Structural Use, British Standards Institution, BSI, Milton Keynes.

BS 5756 (1997) Specification for Visual Strength Grading of Hardwood, British Standards Institution, BSI, Milton Keynes.

CEN (1997) EN 518. Structural Timber. Grading. Requirements for Visual Strength Grading Standards, European Committee for Standardization, Brussels.

CEN (2000) prEN 14081-1. Timber Structures - Strength Graded Structural Timber with Rectangular Cross-Section Part 1: General Requirements, European Committee for Standardization, Brussels.

CEN (2002a) EN 13183-1. Moisture Content of a Piece of Sawn Timber - Part 1: Determination by Oven Dry Method, European Committee for Standardization, Brussels.

CEN (2002b) EN 13183-2. Moisture Content of a Piece of Sawn Timber - Part 2: Estimation by Electrical Resistance Method, European Committee for Standardization, Brussels.

CEN (2003a) EN 336. Structural Timber - Coniferous and Poplar - Sizes, Permissible Deviations, European Committee for Standardization, Brussels.

CEN (2003b) EN 338. Structural Timber. Strength Classes, European Committee for Standardization, Brussels.

CEN (2003c) EN 408. Timber Structures. Structural Timber and Glued Laminated Timber. Determination of Some Physical and Mechanical Properties, European Committee for Standardization, Brussels.

CEN (2004a) EN 1995-1-1. Eurocode 5 - Design of Timber Structures - Part 1-1: General - Common Rules and Rules for Buildings, European Committee for Standardization, Brussels.

CEN (2004b) EN 384. Structural Timber - Determination of Characteristic Values of Mechanical Properties and Density. Part 1: General Requirements, European Committee for Standardization, Brussels.

DIN 4074 (2003). Sortierung von Holz nach der Tragfähigkeit — Teil 1: Nadelschnittholz.

Dunlap, M.E. and Bell, E.R. (1951) Electrical Moisture Meters for Wood. US Department of Agriculture, Forest Products Laboratory Report M. R1160, Madison, WI, USA.

FPL. Forest Products Laboratory (1999) Wood Handbook-Wood as an Engineering Material, US Department of Agriculture, Forest Service, Forest Products Laboratory, Madison, WI.

Foresti, A. (2006) Indagini non distruttive su elementi lignei in opera (NDT on timber members on site) Master Thesis, Ingegneria civile, University of Trento.

Giordano, G. (1999) Tecnica delle costruzioni in legno, Hoepli, Milano.

Görlacher, V.R. (1987) 'Zerstörungsfreie Prüfung von Holz: ein in Situ Verfahren zur Bestimmung der Rohdichte', Holz als Roh- und Werkstoff, 45(7), 273-278.

Hanhijärvi, A., RantaMaunus, A. and Turk, G. (2005) Potential of Strength Grading of Timber with Combined Measurement Techniques. Report of the Combigradeproject — phase 1. VTT publications 568.

Jayne, B.A. (1959) 'Vibrational properties of wood as indices of quality', Forest Product Journal, 5, 259-301.

Kasal, B. and Anthony, R.W. (2004) 'Advances in in situ evaluation of timber structures', Progress in Structural Engineering and Materials, 6, 94-103. 
Kollmann, F.F.P. and Côté, W.A. (1984) Principle of Wood Science and Technology. Vol. I: Solid Wood, Springer-Verlag, Berlin.

Luxford, R.F. (1918) The Influence of Spiral Grain and Diagonal Grain on the Mechanical Properties of Sitka Spruce and Douglas Fir. Report, 228-4, US Dept of Agriculture, Forest Service, Forest Products Laboratory, Madison, WI.

Macchioni, N. and Piazza, M. (2006) 'Italian standardisation activity in the field of diagnosis and restoration of Ancient timber structures', in Lourenço, P.B., Roca, P., Modena, C. and Agrawal, S. (eds) Structural Analysis of Historical Constructions, Macmillan India Ltd., New Delhi.

Madsen, B. (1992) Structural Behaviour of Timber, Timber Engineering Ltd., North Vancouver.

Pezzo, M.I. and Zamatteo Gerosa, A. (2006) 'Analisi dendrocronologica di alcune di travi del rifugio Ai Caduti dell'Adamello, Lobbia Alta, Trentino'. Annali del Museo civico di Rovereto, Year 2005.

Piazza, M. and Del Senno, M. (2001) 'Proposals and criteria for the preliminary evaluation, the design and the execution of works on ancient load bearing timber structures', Wooden Handwork/Wooden Carpentry, European Restoration Sites, Elsevier Applied Science, Paris, pp. 263-277.

Piazza, M. and Turrini, G. (1983) 'Il recupero dei solai in legno, Esperienze e realizzazioni', In Recuperare, 7.

Piazza, M., Tomasi, R. and Modena, R. (2005) Strutture in legno (Timber Structures), Hoepli, Milano.

Pope, D.J., Marcroft, J.P. and Whale, L.R.J. (2005) 'The effect of global slope of grain on the ending strength of scaffold boards', Holz als Roh- und Werkstoff, 63, 321-326.

RILEM International Union of Laboratories and Experts in Construction Materials, Systems and Structures, website http://rilem.net, accessed 1st June, 2007.

Rinn, F. (1992) 'Chancen und Grenzen bei der Untersuchung von Konstruktionshölzern mit der Bohrwiderstandsmethode', Bauen mit Holz, 9, 745-748.

Sandoz, J.L. (1993) 'Moisture content and temperature effect on ultrasound timber grading', Wood Science and Technology, 27, 373-380.

Sandoz, J.L. (1989) 'Grading of construction timber by ultrasound', Wood Science and Technology, 23, 95-108.

SIA 265/1 (2003). Timber Structures - Supplementary Specifications. Association Suisse de Normalisation, Société Suisse des Ingénieurs et des Architectes, Zurich.

Sunley, J.G. (1968) Grade Stresses for Structural Timber. Forest Products Research Laboratory, Bulletin, 47. Thelandersson, S. and Larsen, H.J. (2003) Timber Engineering, John Wiley \& Sons Ltd, Chichester, England.

UNI 11035-1 (2003). Legno strutturale - Classificazione a vista di legnami italiani secondo la resistenza meccanica: terminologia e misurazione delle caratteristiche caratteristiche (Structural Timber - Visual Strength Grading: Terminology and Measurement of Features). Ente Nazionale Italiano di Unificazione, Milano.

UNI 11035-2 (2003). Legno strutturale - Regole per la classificazione a vista secondo la resistenza e i valori caratteristici per tipi di legname strutturale italiani (Visual Strength Grading Rules and Characteristic Values for Italian Structural Timber Population). Ente Nazionale Italiano di Unificazione, Milano.

UNI 11119 (2004). Cultural Heritage — Wooden Artifacts — Load-Bearing Structures - On Site Inspections for the Diagnosis of Timber Members. Ente Nazionale Italiano di Unificazione, Milano.

UNI EN 14251 (2004). Structural Round Timber - Test Methods. Ente Nazionale Italiano di Unificazione, Milano. Weibull, W. (1939) 'A statistical theory of the strength of materials', Proceedings of the Royal Swedish Institute of Engineering Research, N.151, Stockholm.

Wellner, C.A. (1960) 'Devices to measure spiral grain and twisting in poles', Journal of Forestry, 58, 117-118. Wilson, T.R.C. (1921) 'The effect of spiral grain on the strength of wood', Journal of Forestry, XIX(7), 740-747.

Zhou, H. and Smith, I. (1991) 'Factors influencing bending properties of white spruce lumber', Wood Fiber Science, 23, 483-500.

Zombori, B. (2000) 'In situ nondestructive testing of built in wooden members', NDT.net, 6(3). 